\title{
Synthesis and Characterization of AICAR and DOX Conjugated Multifunctional Nanoparticles as a Platform for Synergistic Inhibition of Cancer Cell Growth
}

\author{
Cenk Daglioglu* ${ }^{\dagger, \dagger}$ and Burcu Okutucu ${ }^{\dagger}$ \\ ${ }^{\dagger}$ Ege University, Faculty of Science, Biochemistry Department, Bornova/Izmir 35040, Turkey \\ ${ }^{\ddagger}$ Izmir Institute of Technology, Faculty of Science, Department of Molecular Biology and Genetics, Urla/Izmir 35430, Turkey
}

\begin{abstract}
The success of cancer treatment depends on the response to chemotherapeutic agents. However, malignancies often acquire resistance to drugs if they are used frequently. Combination therapy involving both a chemotherapeutic agent and molecularly targeted therapy may have the ability to retain and enhance therapeutic efficacy. Here, we addressed this issue by examining the efficacy of a novel therapeutic strategy that combines AICAR and DOX within a multifunctional platform. In this context, we reported the bottom-up synthesis of $\mathrm{Fe}_{3} \mathrm{O}_{4} @ \mathrm{SiO}_{2}$ (FITC)-FA/AICAR/ DOX multifunctional nanoparticles aiming to neutralize survivin (BIRC5) to potentiate the efficacy of DOX against chemoresistance. The structure of nanoparticles was charac-

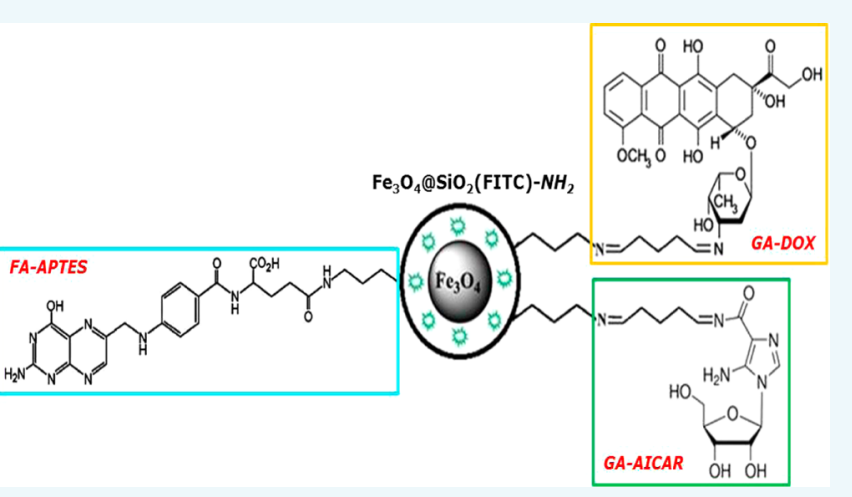
terized by dynamic light scattering (DLS), zeta-potential measurement, X-ray diffraction (XRD), Fourier transform infrared spectroscopy (FT-IR), thermogravimetric analysis (TGA), and electron microscopy (SEM and STEM with EDX) techniques. Cellular uptake and cytotoxicity experiments demonstrated preferentially targeted delivery of nanoparticles and an efficient reduction of cancer cell viability in five different tumor-derived cell lines (A549, HCT-116, HeLa, Jurkat, and MIA PaCa-2). These results indicate that the multifunctional nanoparticle system possesses high inhibitory drug association and sustained cytotoxic effect with good biocompatibility. This novel approach which combines AICAR and DOX within a single platform might be promising as an antitumor treatment for cancer.
\end{abstract}

\section{INTRODUCTION}

Chemotherapy is one of the principal modes of treatment for cancer, but the effectiveness of chemotherapy is limited by drug resistance. ${ }^{1}$ Chemotherapeutic agents are generally used in combination with a maximum tolerated dose to eliminate drug resistance and then to achieve maximum cancer cell killing. ${ }^{2}$ However, most patients do not respond to these drugs and they often experience severe adverse effects because of greater toxicity compared to each drug alone. ${ }^{3}$ One of the major factors responsible for chemoresistance is the evolution of the tumor cells toward a phenotype that is resistant to apoptotic cell kill. On a molecular level, increased expression of the inhibitor of apoptosis protein family (IAPs) has been detected in this phenotype. ${ }^{4}$ Therefore, interfering with IAPs expression or function is a new strategy to eliminate drug resistance. Survivin, a structurally unique member of the IAP family that acts as a suppressor of apoptosis and plays a central role in cell division, is overexpressed in all human cancers, but demonstrates low expression in normal tissues. ${ }^{5}$ Several preclinical studies in different human tumor models have demonstrated that downregulation of survivin expression or function, accomplished by means of various strategies, reduced tumor growth potential, increased the apoptotic rate, and sensitized tumor cells to chemotherapeutic drugs. ${ }^{6}$ Heat shock protein 90 (Hsp90) is a significant target in the development of rational cancer therapy due to its role at the crossroads of multiple signaling pathways associated with cell proliferation and cell viability. Through combined structure- and dynamicsbased computational design strategy and experimental tests, Meli et al. reported that the nonpeptidic small molecule 5 -aminoimidazole-4-carboxamide-1- $\beta$-D-ribofuranoside (AICAR) binds the Hsp90 N-domain, destabilizes multiple Hsp90 client proteins in vivo, including survivin, and exhibits antiproliferative and proapoptotic activity in multiple tumor cell lines, while not affecting proliferation of normal human fibroblasts. ${ }^{7}$ Doxorubicin (DOX) is a common chemotherapeutic used in the treatment of a wide range of cancers because of its excellent antitumor activity. ${ }^{8}$ Resistance to this agent impairs treatment of cancer patients and prevents successful treatment. ${ }^{9}$ In addition, DOX has a relatively low therapeutic index and its clinical usage is limited due to acute and chronic toxicities such as immunosuppression and cardiotoxicity. ${ }^{10}$ Therefore, more efficient treatment strategies must be developed that reduce or eliminate drug resistance,

Received: February 11, 2016

Revised: $\quad$ March 17, 2016

Published: March 20, 2016 


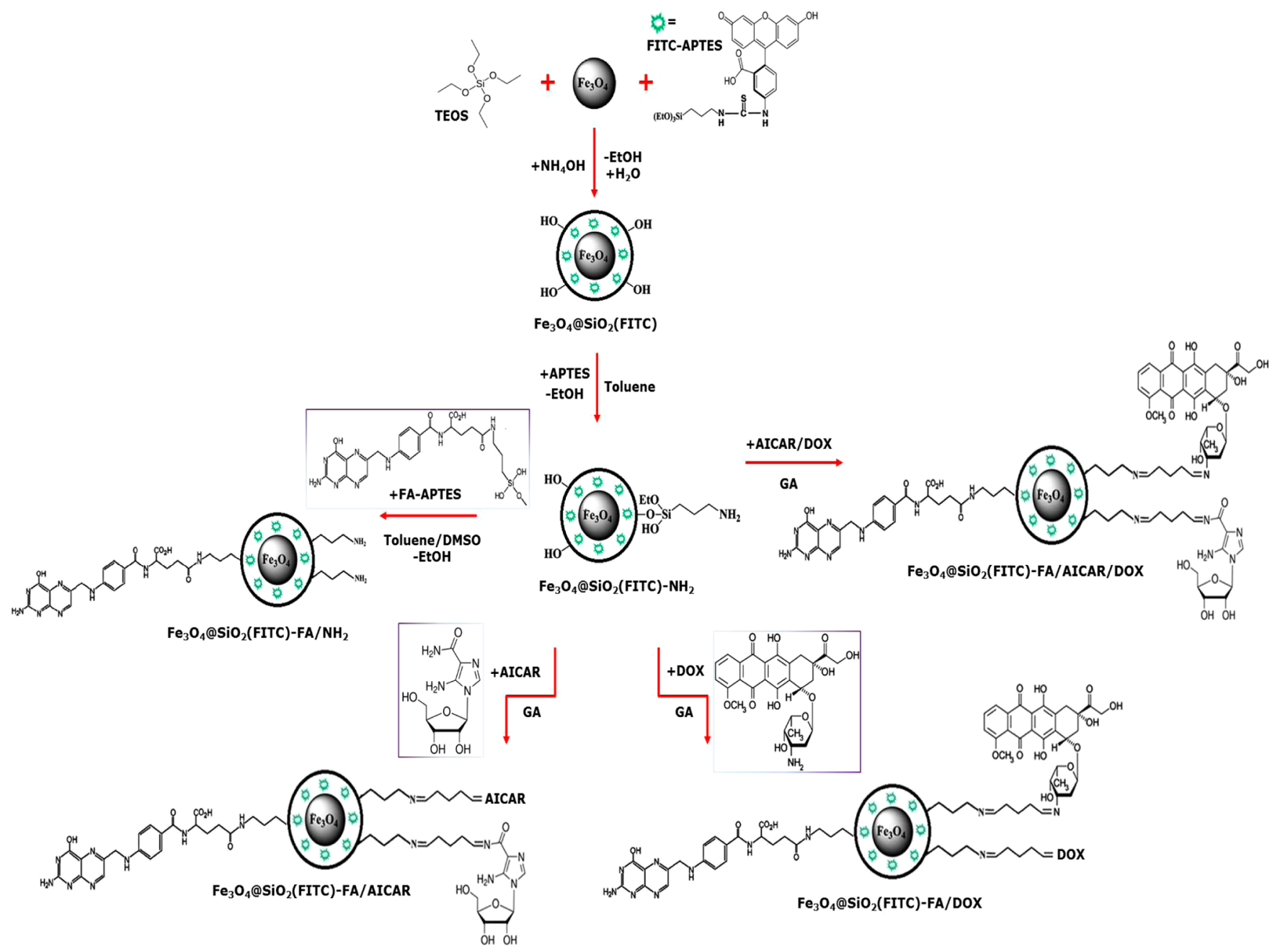

Figure 1. Reaction schemes to generate (1) $\mathrm{Fe}_{3} \mathrm{O}_{4} @ \mathrm{SiO}_{2}(\mathrm{FITC})$; (2) $\mathrm{Fe}_{3} \mathrm{O}_{4} @ \mathrm{SiO}_{2}(\mathrm{FITC})-\mathrm{FA} / \mathrm{NH}_{2} ;$ (3) $\mathrm{Fe}_{3} \mathrm{O}_{4} @ \mathrm{SiO}_{2}(\mathrm{FITC})$-FA/AICAR; (4) $\mathrm{Fe}_{3} \mathrm{O}_{4} @ \mathrm{SiO}_{2}$ (FITC)-FA/DOX; and (5) $\mathrm{Fe}_{3} \mathrm{O}_{4} @ \mathrm{SiO}_{2}$ (FITC)-FA/AICAR/DOX nanoparticles.

decrease the cytotoxic effects of DOX, and also enhance therapeutic efficacy. Considering the potential value of reducing or abolishing survivin expression as a means of overcoming chemoresistance, we have successfully developed a core/shell type of nanoparticle formulation to codeliver AICAR and DOX, thereby enhancing antitumor activity while reducing chemoresistance.

In recent years, multifunctional particles with magnetism, fluorescence, and target navigation have been explored extensively in biomedical applications. They have been developed as an all-in-one biomedical platform for simultaneous fluorescence imaging, manipulation of cells, and drug delivery tools. ${ }^{11-14}$ Among the various multifunctional particles, dye-doped silica magnetic-fluorescent composites are very promising biomedical materials due to the following advantages: (1) their high photostability and relatively strong fluorescent signal owing to their high dye-incorporation capabilities and stabilization in a protective silica matrix with biocompatibility and less toxicity; (2) superparamagnetic oxide iron nanoparticles with fast magnetic response making it easy to manipulate via an external magnetic field, and this "remote control" providing considerable advantages for many applications; ${ }^{15}$ (3) contrast agents with both optical and magnetic contrast serving as good molecular imaging probes both in vitro and in vivo. ${ }^{16}$ In addition, active targeting of nanoparticles can potentially increase the efficacy and reduce the toxicity of therapeutic agents. ${ }^{17}$ This is achieved by conjugating the surface of nanoparticles using specific cell ligands. Folic acid (FA) has been widely used in the delivery of anticancer agents due to its small size, low cost, high tumor tissue specificity, nonimmunogenic nature, and fast internalization through the cellular membrane. ${ }^{18}$ FA linked nanocarriers have fairly high binding affinity to folate receptors (FR) expressed on tumor cells. ${ }^{19}$

In this study we have rationally designed the bottom-up synthesis of four successive nanoparticles: (1) $\mathrm{Fe}_{3} \mathrm{O}_{4} @ \mathrm{SiO}_{2}$ (FITC)-FA nanoparticles noncontaining any inhibitor or drug; (2) $\mathrm{Fe}_{3} \mathrm{O}_{4} @$ $\mathrm{SiO}_{2}$ (FITC)-FA/AICAR nanoparticles containing only inhibitor; (3) $\mathrm{Fe}_{3} \mathrm{O}_{4} @ \mathrm{SiO}_{2}$ (FITC)-FA/DOX nanoparticles containing only drug; (4) $\mathrm{Fe}_{3} \mathrm{O}_{4} @ \mathrm{SiO}_{2}$ (FITC)-FA/AICAR/DOX nanoparticles containing both inhibitor and drug to evaluate synergistic potential of therapeutics. The feasibility of nanoparticles was evaluated by investigating their capability in cellular uptake, fluorescent imaging, and cytotoxic effect in five different tumor-derived cell lines (A549, HCT-116, HeLa, Jurkat, and MIA PaCa-2). To the best of our knowledge, this is the first study which combines AICAR and DOX as therapeutic agents and examines their synergetic effect within a multifunctional platform. The preliminary cell tests confirm the potential of these multifunctional nanoparticles as an antitumor treatment in cancer therapy. 
Table 1. Immobilization Yields of AICAR and DOX on Silica Surface

\begin{tabular}{|c|c|c|c|}
\hline immobilization method & $\begin{array}{l}\text { GA concentration } \\
(\%)\end{array}$ & $\begin{array}{c}\text { AICAR and DOX } \\
\text { immobilization yield (\%) }\end{array}$ & $\begin{array}{l}\text { AICAR and DOX immobilization concentration } \\
(\mu \mathrm{M} \text { per mg nanoparticles })\end{array}$ \\
\hline \multirow{2}{*}{$\mathrm{Fe}_{3} \mathrm{O}_{4} @ \mathrm{SiO}_{2}(\mathrm{FITC})-\mathrm{FA} / \mathrm{AICAR}$} & 0.1 & 6.8 & 1.3 \\
\hline & 1.0 & 30.5 & 6.1 \\
\hline \multirow[t]{2}{*}{$\mathrm{Fe}_{3} \mathrm{O}_{4} @ \mathrm{SiO}_{2}$ (FITC)-FA/DOX } & 0.1 & 10.1 & 0.2 \\
\hline & 1.0 & 51.5 & 1.0 \\
\hline \multirow[t]{2}{*}{$\mathrm{Fe}_{3} \mathrm{O}_{4} @ \mathrm{SiO}_{2}(\mathrm{FITC})-\mathrm{FA} / \mathrm{AICAR} / \mathrm{DOX}$} & 0.1 & $11.2_{(\mathrm{AICAR})} / 10.5_{(\mathrm{DOX})}$ & $2.2_{(\mathrm{AICAR})} / 0.2_{(\mathrm{DOX})}$ \\
\hline & 1.0 & $22.5_{(\text {AICAR })} / 35.7_{(\mathrm{DOX})}$ & $4.5_{(\mathrm{AICAR})} / 0.7_{(\mathrm{DOX})}$ \\
\hline
\end{tabular}

\section{RESULTS AND DISCUSSION}

Synthesis and Characterization of Multifunctional Nanoparticles. To construct the nanoparticles, silica $\left(\mathrm{SiO}_{2}\right)$ was used for surface coating of $\mathrm{F}_{3} \mathrm{O}_{4}$ particles because dye molecules can be easily incorporated into a silica shell, and silica is quite biocompatible and resistant to biodegradation in biological environments. ${ }^{24}$ In addition, silica can be easily surface functionalized for bioconjugation and targeted for various applications in biological systems. Hence, in this study we first synthesized bifunctional nanoparticles, $\mathrm{F}_{3} \mathrm{O}_{4} @$ $\mathrm{SiO}_{2}$ (FITC) (Figure 1) with both fluorescent and magnetic properties by sol-gel formation of the silica layer onto the magnetite surface. To increase the cellular uptake of magnetic iron oxide particles, nanoparticles were vectorized with folic acid by silanization FA-APTES conjugate on the silica surface and simultaneously the surfaces were modified with free APTES to form an amine-terminated overlayer for the subsequent conjugation of both AICAR and DOX via Schiff-base formation. In general, two different approaches have been explored for drug transportation by nanoparticles. The first consists of conjugating the drugs covalently to the nanoparticle surface through appropriate linkers, and the second in physically adsorbing or establishing ionic and hydrogen bonds. The covalent method is the most used because the bond strength makes nanoparticle-drug conjugates highly stable. $^{25}$ Thus, after surface modification with APTES, AICAR and DOX were covalently linked on the surface of nanoparticles from their amine group using glutaraldehyde as a linker. In this step, different concentrations of glutaraldehyde were tested separately to determine the optimal linker concentration (Table 1). Among the tested amounts of glutaraldehyde, the highest coupling yield of AICAR and DOX complexes was observed at $1 \%$ glutaraldehyde concentration. The amount of bound AICAR or DOX was calculated from the difference between the amount of AICAR or DOX introduced into the coupling reaction mixture and the amount of AICAR or DOX present in the washing water after immobilization by measuring AICAR or DOX absorbance at 260 and $480 \mathrm{~nm}$, respectively.

The average hydrodynamic diameter of the oleic acid stabilized $\mathrm{Fe}_{3} \mathrm{O}_{4}$ nanoparticles, determined for 0.1/0.2/0.4/0.6 mL concentrations of oleic acid by DLS, were $4.9 \pm 1.2,7.8 \pm 1.5$, $12.1 \pm 3.8$, and $18.7 \pm 7 \mathrm{~nm}$, respectively. Since oleic acid effectively regulates $\mathrm{Fe}_{3} \mathrm{O}_{4}$ nanoparticle growth and prevents aggregation, different amounts of oleic acid were tested to produce size-controlled monodisperse $\mathrm{Fe}_{3} \mathrm{O}_{4}$ nanoparticles. The nanoparticle sizes increased regularly with increasing amount of oleic acid, due to increased chemisorption of oleate ions on the magnetite particles. Therefore, we chose the nanoparticles stabilized with $0.1 \mathrm{~mL}$ oleic acid in the next study to obtain the proper nanoparticles with narrow size distribution. The silica coating led to an increase of the average particle size $(\sim 17 \mathrm{~nm})$ (Table 2$)$. After the immobilization
Table 2. Size and Zeta Potential of the Multifunctional Nanoparticles

\begin{tabular}{lcc}
\multicolumn{1}{c}{ nanoparticles } & size $(\mathrm{nm})$ & zeta potential $(\mathrm{mV})$ \\
$\mathrm{Fe}_{3} \mathrm{O}_{4} @ \mathrm{SiO}_{2}$ (FITC) & $17.2 \pm 3.5$ & $-17.5 \pm 1.1$ \\
$\mathrm{Fe}_{3} \mathrm{O}_{4} @ \mathrm{SiO}_{2}$ (FITC)-FA/NH $\mathrm{NH}_{2}$ & $29.7 \pm 6.2$ & $+5.3 \pm 2.3$ \\
$\mathrm{Fe}_{3} \mathrm{O}_{4} @ \mathrm{SiO}_{2}$ (FITC)-FA/AICAR & $53.5 \pm 6.7$ & $-9.1 \pm 1.6$ \\
$\mathrm{Fe}_{3} \mathrm{O}_{4} @ \mathrm{SiO}_{2}$ (FITC)-FA/DOX & $62.5 \pm 8.6$ & $-8.4 \pm 1.5$ \\
$\mathrm{Fe}_{3} \mathrm{O}_{4} @ \mathrm{SiO}_{2}$ (FITC)-FA/AICAR/DOX & $79.2 \pm 8.2$ & $-11.3 \pm 3.4$ \\
\hline
\end{tabular}

process, the size of nanoparticles attached with both AICAR and DOX increased to approximately $79 \mathrm{~nm}$. Particles with a diameter ranging from 10 to $100 \mathrm{~nm}$ are optimal for intravenous injection and have the most prolonged blood circulation times. These particles are small enough to evade the Reticuloendothelial System (RES) of the body as well as to penetrate small capillaries of the tissues and offer the most effective distribution in targeted tissues. ${ }^{26}$

The zeta potential of nanoparticles was analyzed to confirm the change in their surface potential due to proper biofunctionalization. The stepwise conjugation of functional groups on the silica surface was monitored by measuring the surface charges at different stages of synthesis (Figure 2 and Table 2). A negative zeta potential $(\zeta)$ value of $-17.5 \mathrm{mV}(\mathrm{pH} 7.4)$ of $\mathrm{Fe}_{3} \mathrm{O}_{4} @ \mathrm{SiO}_{2}$ (FITC) nanoparticles can be attributed to the presence of ionizable silanol groups of silica surface. After modification with APTES/FA conjugate, the zeta potential value of $\mathrm{Fe}_{3} \mathrm{O}_{4} @ \mathrm{SiO}_{2}$ (FITC)-FA/ $\mathrm{NH}_{2}$ nanoparticles reverted to a positive value $(+5.3 \mathrm{mV}$ at $\mathrm{pH}=7.4)$ due to the presence of an excess of positively charged amino groups. FA is expected to furnish silica surface with negative charge; however, the excess amount of $\mathrm{NH}_{2}$ groups presumably nullify the FA charge and make the overall surface charge slightly positive. Further modification of the surface by conjugating both AICAR or DOX groups reverted the surface charge back to a negative value, for $\mathrm{Fe}_{3} \mathrm{O}_{4} @ \mathrm{SiO}_{2}$ (FITC)-FA/AICAR, $\mathrm{Fe}_{3} \mathrm{O}_{4} @ \mathrm{SiO}_{2}$ (FITC)-FA/ DOX, and $\mathrm{Fe}_{3} \mathrm{O}_{4} @ \mathrm{SiO}_{2}$ (FITC)-FA/AICAR/DOX nanoparticles with average values of $-9.1,-8.4$, and $-11.3 \mathrm{mV}$ obtained at $\mathrm{pH}=7.4$, respectively. These results could be attributed to a function of the ionizability of AICAR and DOX groups on silica surface.

The bulk crystal structure of the nanoparticles was analyzed by X-ray diffraction (XRD) using the Debye-Scherrer method. Figure 3 shows the XRD patterns of the $\mathrm{Fe}_{3} \mathrm{O}_{4}$ and $\mathrm{Fe}_{3} \mathrm{O}_{4} @$ $\mathrm{SiO}_{2}$ (FITC) nanoparticles. For $\mathrm{Fe}_{3} \mathrm{O}_{4}$ magnetic particles, XRD spectra showed the six characteristic peaks occurring at $2 \theta$ of $30.1,35.5,43.1,53.4,57.0$, and 62.6, which are marked by their corresponding indices (220), (311), (400), (422), (511), and (440), respectively. These results were in excellent agreement with the JCPDS file for $\mathrm{Fe}_{3} \mathrm{O}_{4}$ (Card No. \#19-629). This analysis revealed that the prepared magnetic particles are pure $\mathrm{Fe}_{3} \mathrm{O}_{4}$ with a cubic spinel structure. For $\mathrm{Fe}_{3} \mathrm{O}_{4} @ \mathrm{SiO}_{2}$ (FITC) nanoparticles, the same six characteristic peaks corresponding 

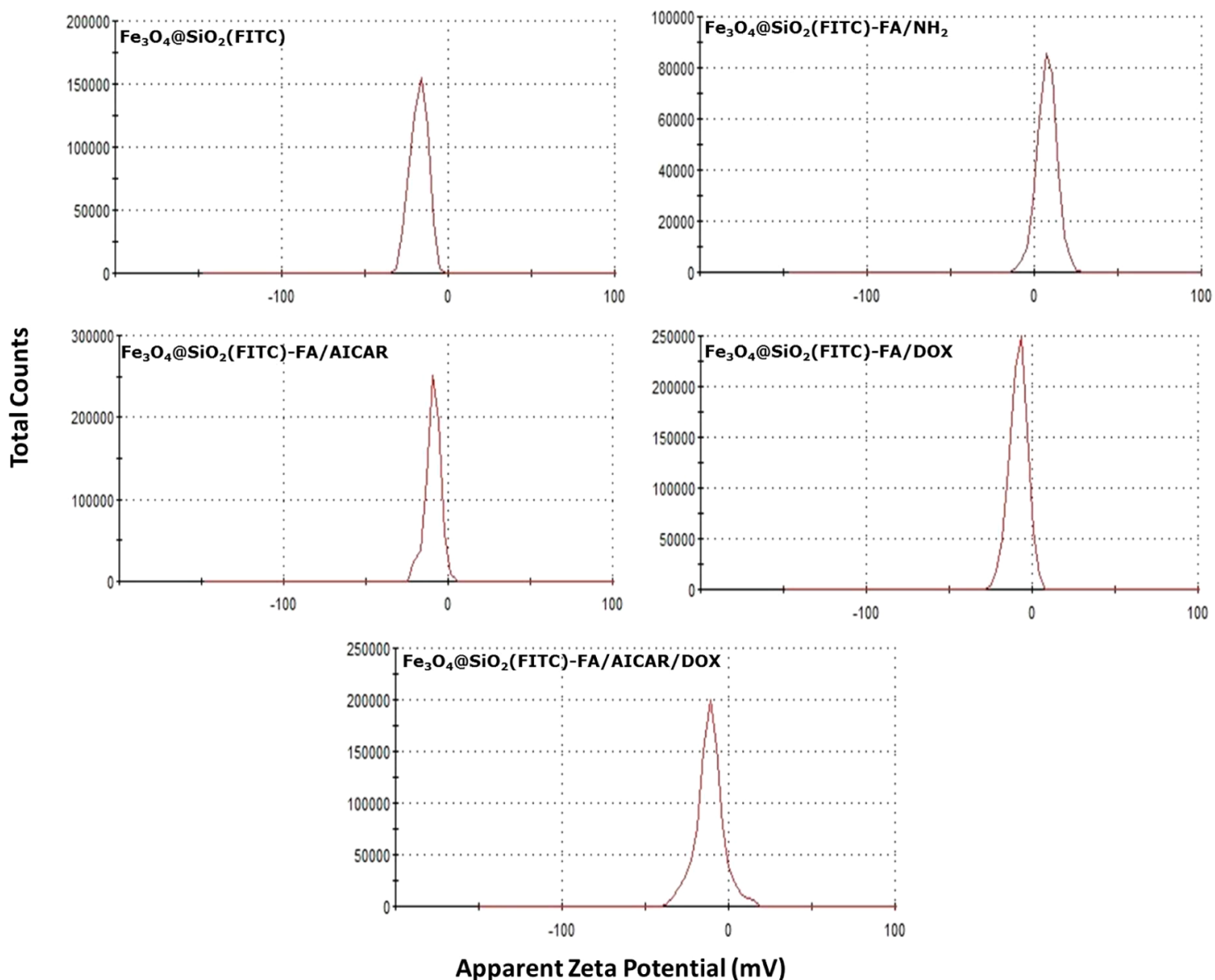

Figure 2. Zeta potential measurements of (1) $\mathrm{Fe}_{3} \mathrm{O}_{4} @ \mathrm{SiO}_{2}(\mathrm{FITC})$; (2) $\mathrm{Fe}_{3} \mathrm{O}_{4} @ \mathrm{SiO}_{2}(\mathrm{FITC})-\mathrm{FA} / \mathrm{NH}_{2}$; (3) $\mathrm{Fe}_{3} \mathrm{O}_{4} @ S \mathrm{SiO}{ }_{2}(\mathrm{FITC})-\mathrm{FA} / \mathrm{AICAR}$; (4) $\mathrm{Fe}_{3} \mathrm{O}_{4} @ \mathrm{SiO}_{2}$ (FITC)-FA/DOX; and (5) $\mathrm{Fe}_{3} \mathrm{O}_{4} @ \mathrm{SiO}_{2}$ (FITC)-FA/AICAR/DOX nanoparticles obtained at pH = 7.4 using DLS.

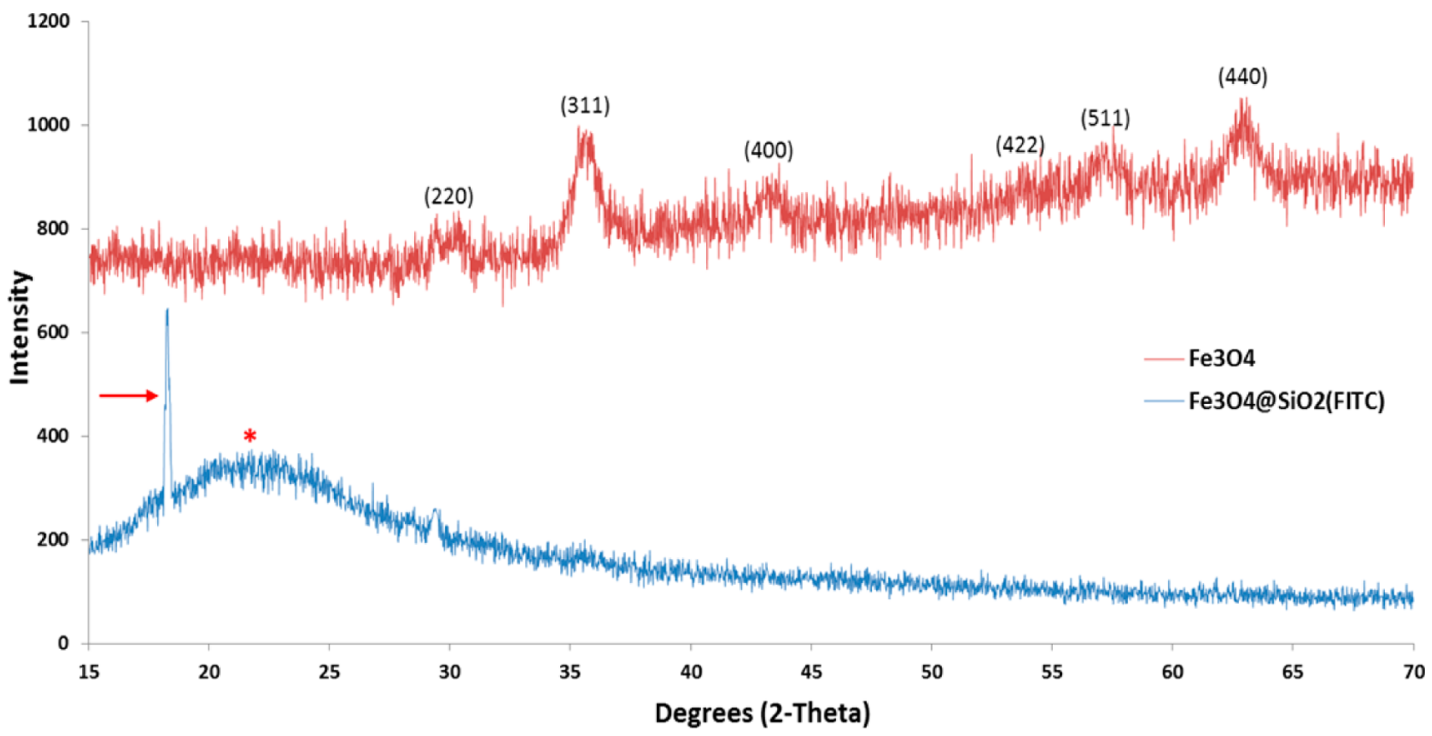

Figure 3. Powder XRD patterns of $\mathrm{Fe}_{3} \mathrm{O}_{4}$ and $\mathrm{Fe}_{3} \mathrm{O}_{4} @ \mathrm{SiO}_{2}$ (FITC) nanoparticles. The position of the peak of FITC and the broad peak of amorphous silica are marked with a red arrow and asterisk $(*)$, respectively.

to uncoated $\mathrm{Fe}_{3} \mathrm{O}_{4}$ were significantly masked and a broad peak ranging from $15^{\circ}$ to $30^{\circ}$ confirmed the presence of an amorphous silica shell surrounding the $\mathrm{Fe}_{3} \mathrm{O}_{4}$ magnetic core. ${ }^{27}$ This result indicated that the silica coating did not cause a phase change in the magnetic particles. Therefore, the magnetic particles could preserve their magnetic properties for further applications. Simultaneously, the characteristic peak at $2 \theta$ of $18.1^{\circ}$ was observed for the fluorescent FITC, which exists in the silica layer in samples. ${ }^{28}$

The surface modification and conjugation of nanoparticles with APTES, FA, AICAR, and DOX were confirmed by Fourier transform infrared (FTIR) spectroscopy. For comparison, 

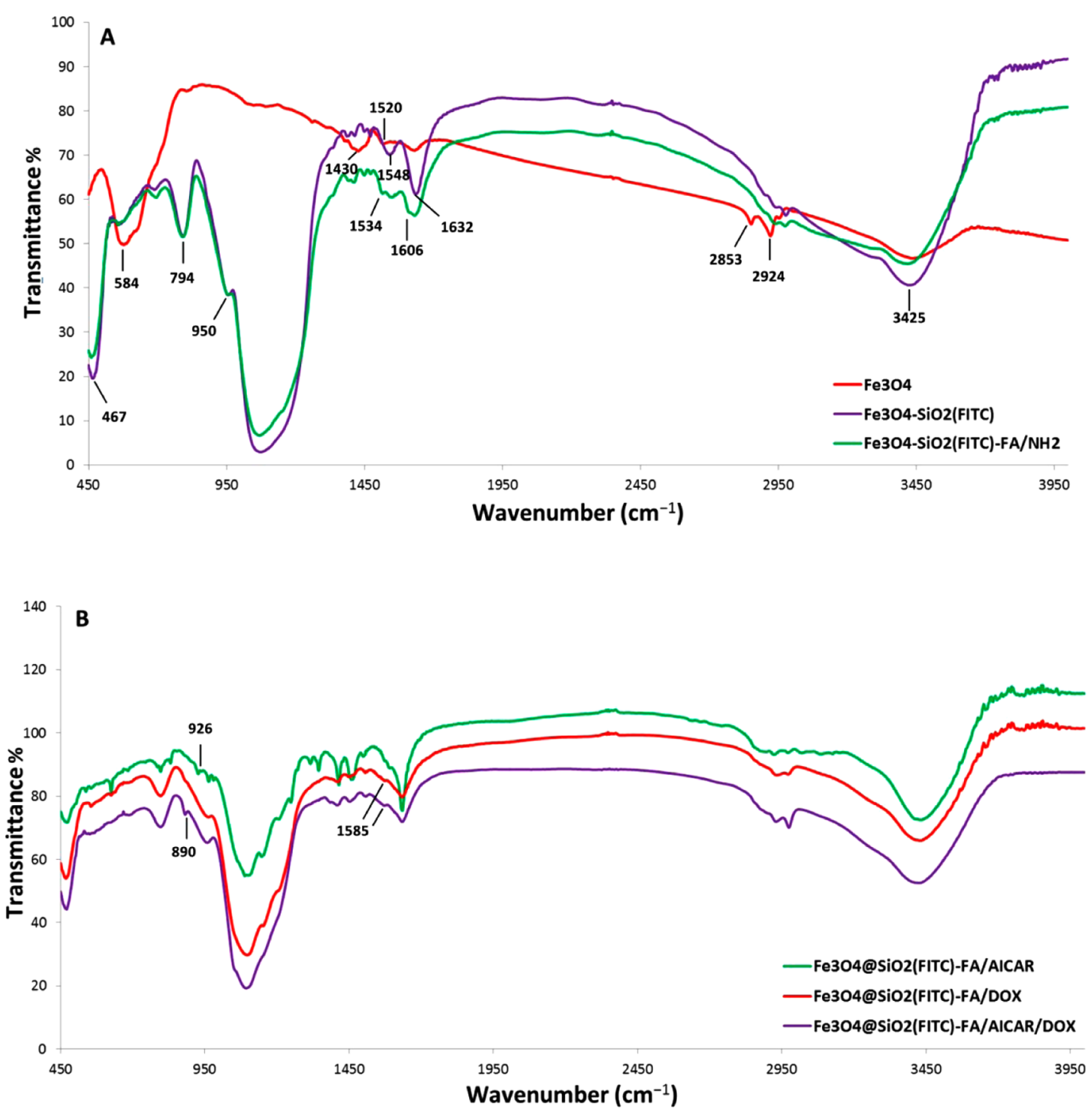

Figure 4. FTIR characterization of (A) $\mathrm{Fe}_{3} \mathrm{O}_{4}, \mathrm{Fe}_{3} \mathrm{O}_{4} @ \mathrm{SiO}_{2}$ (FITC), $\mathrm{Fe}_{3} \mathrm{O}_{4} @ \mathrm{SiO}_{2}$ (FITC)-FA/ $\mathrm{NH}_{2}$; (B) $\mathrm{Fe}_{3} \mathrm{O}_{4} @ \mathrm{FSiO}_{2}$ (FITC)-FA/AICAR, $\mathrm{Fe}_{3} \mathrm{O}_{4} @ \mathrm{SiO}_{2}$ (FITC)-FA/DOX, and $\mathrm{Fe}_{3} \mathrm{O}_{4} @ \mathrm{SiO}_{2}$ (FITC)-FA/AICAR/DOX nanoparticles.

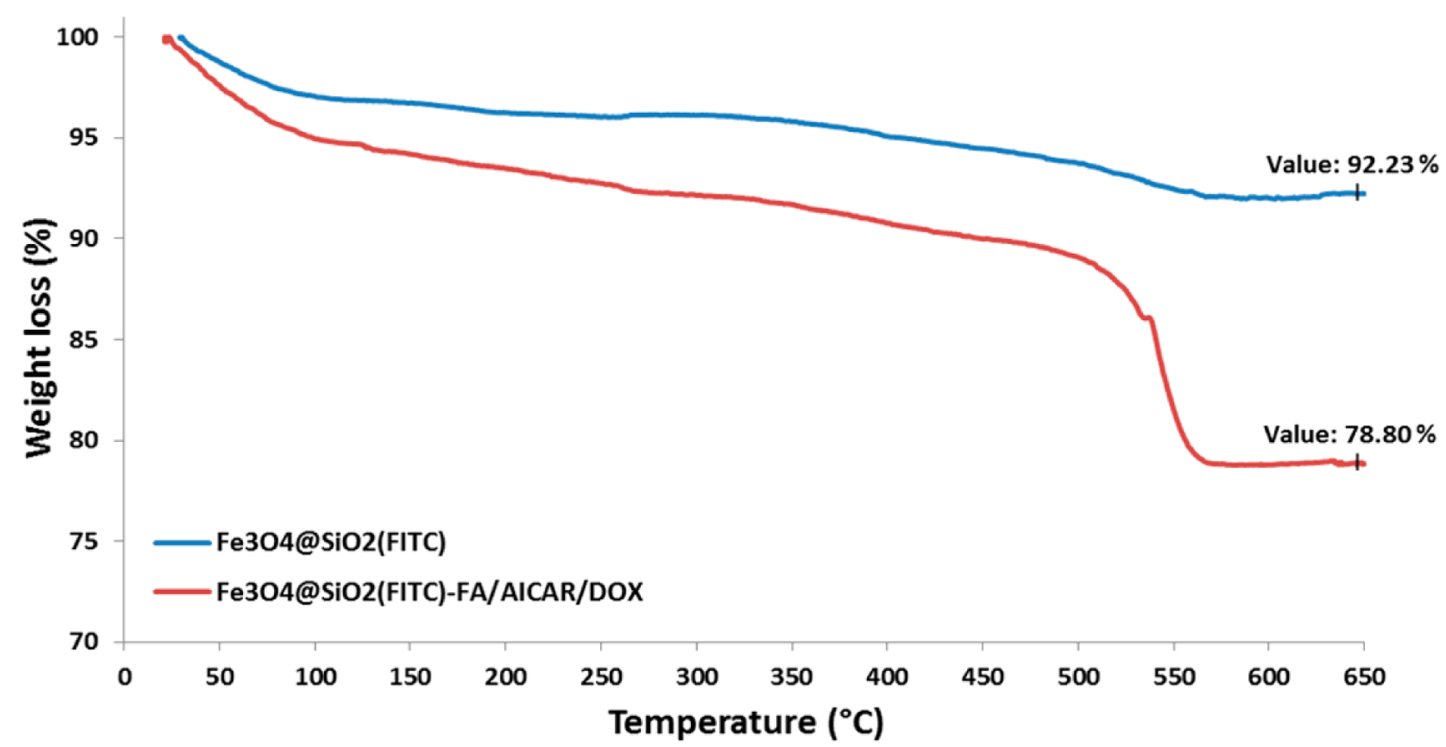

Figure 5. TGA trace of $\mathrm{Fe}_{3} \mathrm{O}_{4} @ \mathrm{SiO}_{2}(\mathrm{FITC})$ and $\mathrm{Fe}_{3} \mathrm{O}_{4} @ \mathrm{SiO}_{2}$ (FITC)-FA/AICAR/DOX nanoparticles. 

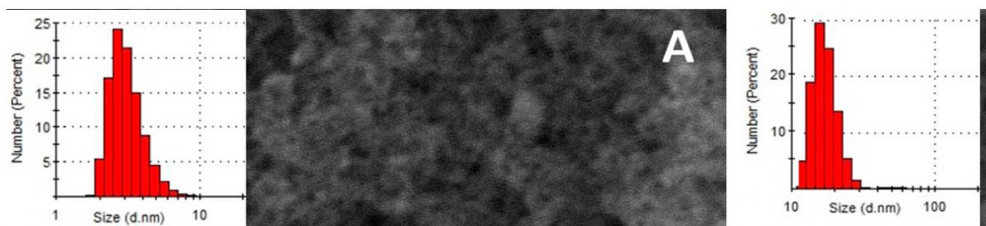

B
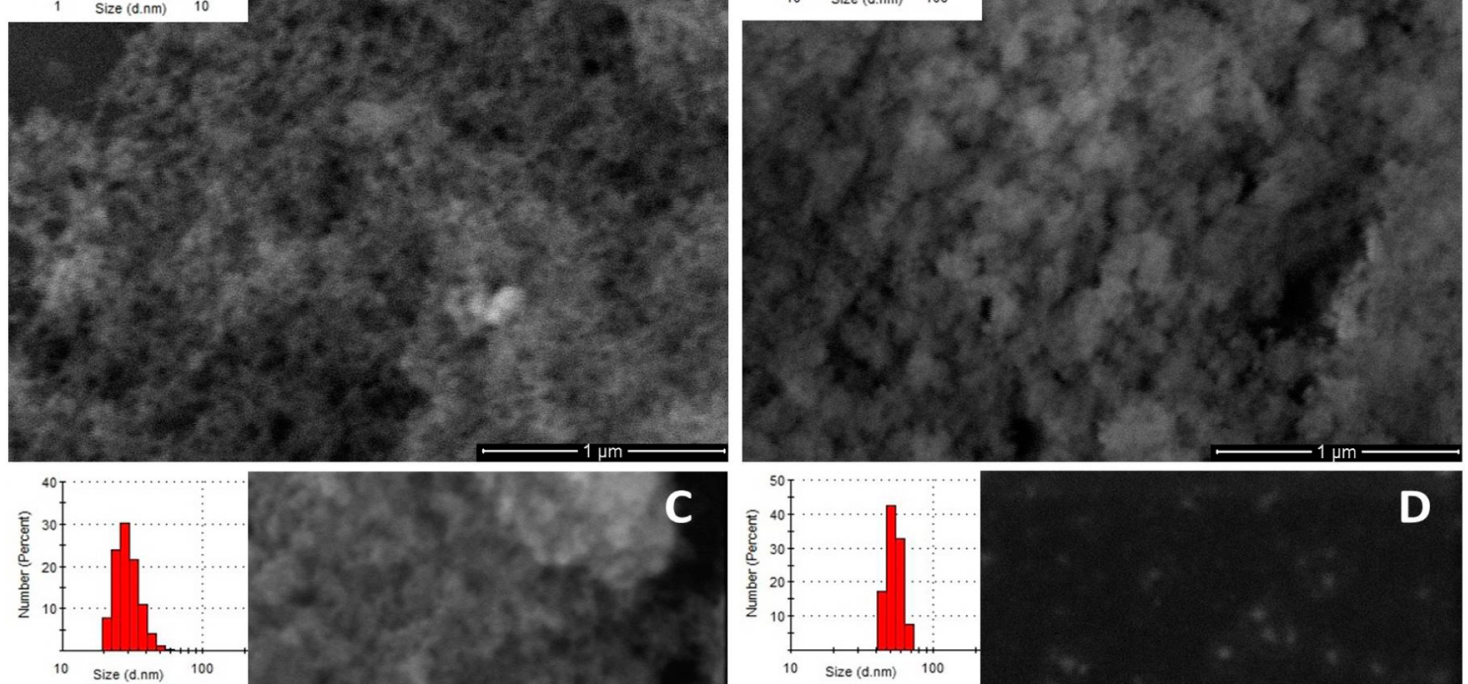

D
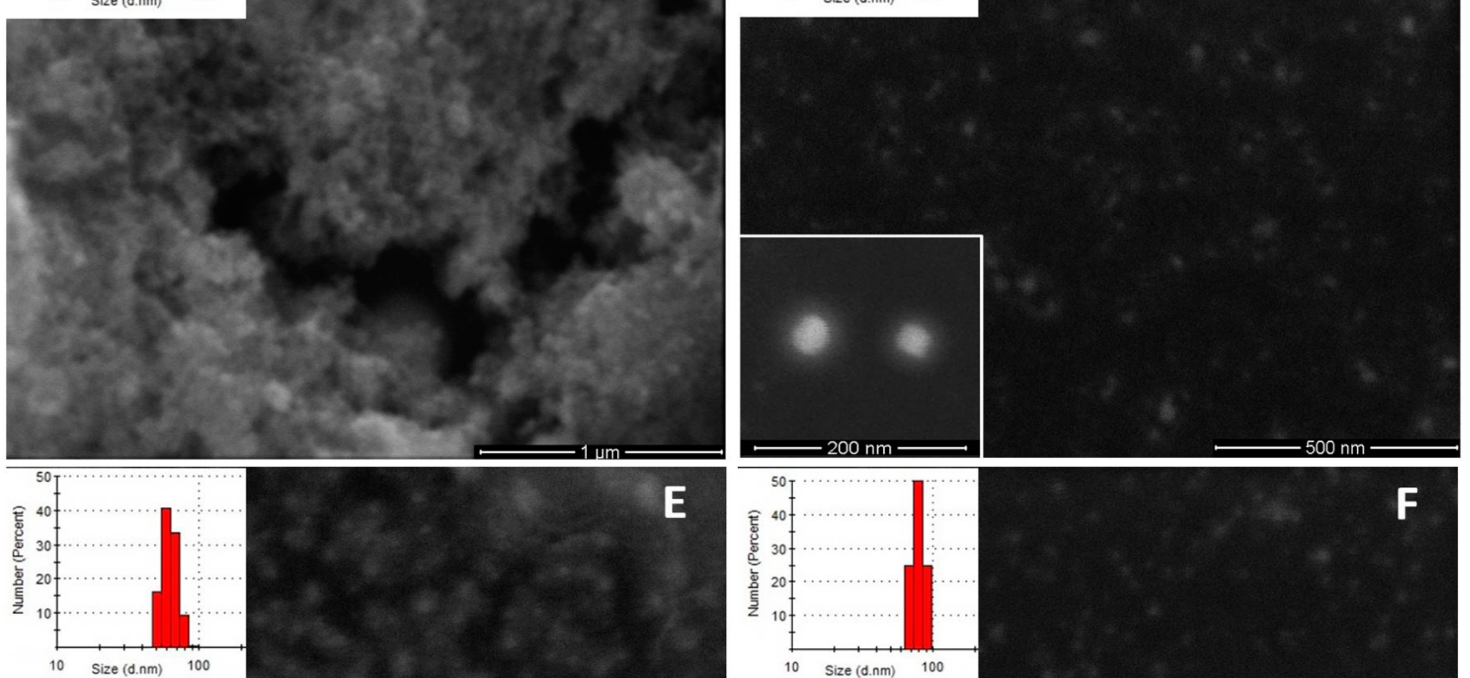

E
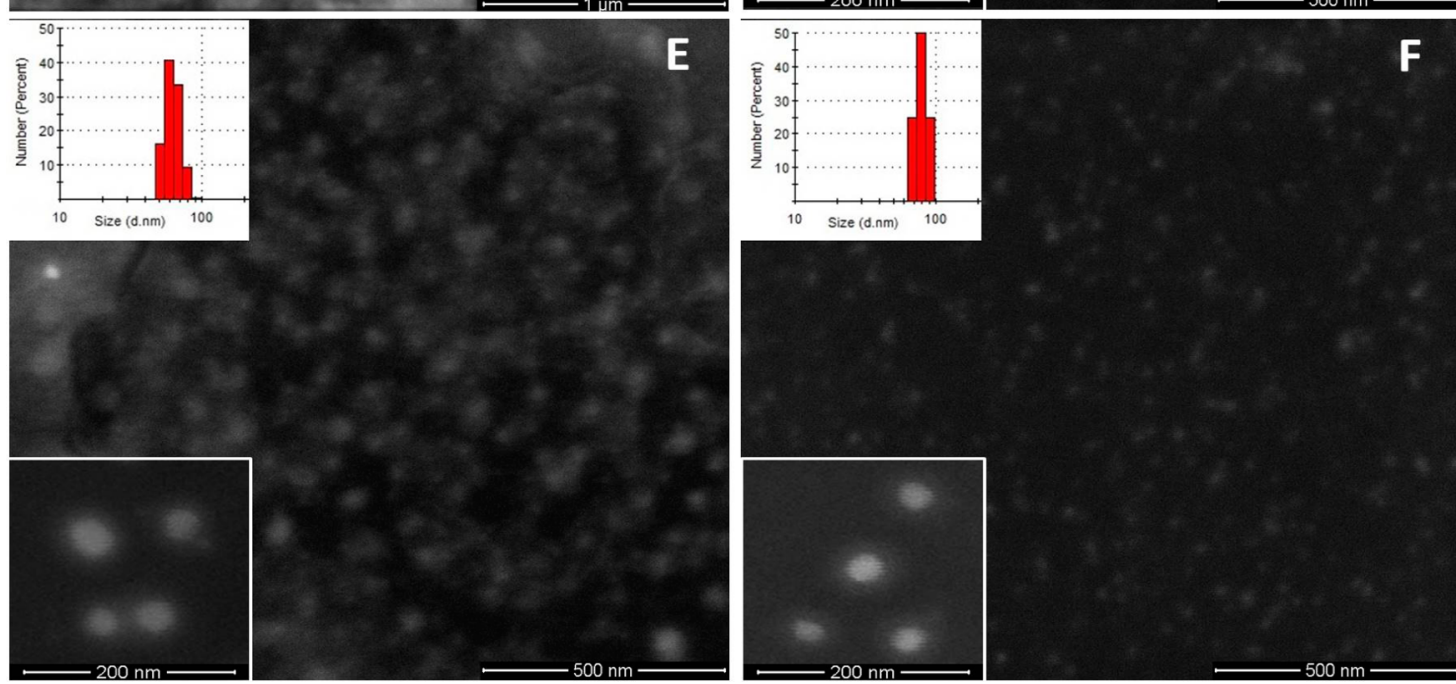

Figure 6. SEM images and size distribution of (a) $\mathrm{Fe}_{3} \mathrm{O}_{4}$, (b) $\mathrm{Fe}_{3} \mathrm{O}_{4} @ \mathrm{SiO}_{2}$ (FITC), (c) $\mathrm{Fe}_{3} \mathrm{O}_{4} @ \mathrm{FiO}_{2}$ (FITC)-FA/NH $\mathrm{N}_{2}$, and STEM images of (d) $\mathrm{Fe}_{3} \mathrm{O}_{4} @ \mathrm{SiO}_{2}$ (FITC)-FA/AICAR, (e) $\mathrm{Fe}_{3} \mathrm{O}_{4} @ \mathrm{SiO}_{2}$ (FITC)-FA/DOX, (f) $\mathrm{Fe}_{3} \mathrm{O}_{4} @ S_{2} \mathrm{SiO}_{2}$ (FITC)-FA/AICAR/DOX nanoparticles.

FTIR spectra of (1) $\mathrm{Fe}_{3} \mathrm{O}_{4},(2) \mathrm{Fe}_{3} \mathrm{O}_{4} @ \mathrm{SiO}_{2}$ (FITC), (3) $\mathrm{Fe}_{3} \mathrm{O}_{4} @ \mathrm{SiO}_{2}$ (FITC)-FA, (4) $\mathrm{Fe}_{3} \mathrm{O}_{4} @ \mathrm{SiO}_{2}$ (FITC)-FA/AICAR, (5) $\mathrm{Fe}_{3} \mathrm{O}_{4} @ \mathrm{SiO}_{2}$ (FITC)-FA/DOX, and (6) $\mathrm{Fe}_{3} \mathrm{O}_{4} @$ $\mathrm{SiO}_{2}$ (FITC)-FA/AICAR/DOX nanoparticles are shown in Figure $4 a / b$.

The two oxygen atoms of $\mathrm{COO}$ in oleic acid provide two coordination positions to form the chemical interaction with $\mathrm{Fe}$ atom. As a result of the chemical interaction, the band $1710 \mathrm{~cm}^{-1}$, which is assigned to the stretching vibration of $\mathrm{C}=\mathrm{O}$ in free oleic acid, disappeared in the FTIR spectra of $\mathrm{Fe}_{3} \mathrm{O}_{4}$ and the asymmetric $\left(-\mathrm{COO}^{-}\right)$and symmetric $\left(-\mathrm{COO}^{-}\right)$ stretch vibration band resulted at 1430 and $1520 \mathrm{~cm}^{-1}$, respectively. The bands at 2853 and $2924 \mathrm{~cm}^{-1}$ are attributed to the asymmetric $\mathrm{CH}_{2}$ stretch and the symmetric $\mathrm{CH}_{2}$ stretch 

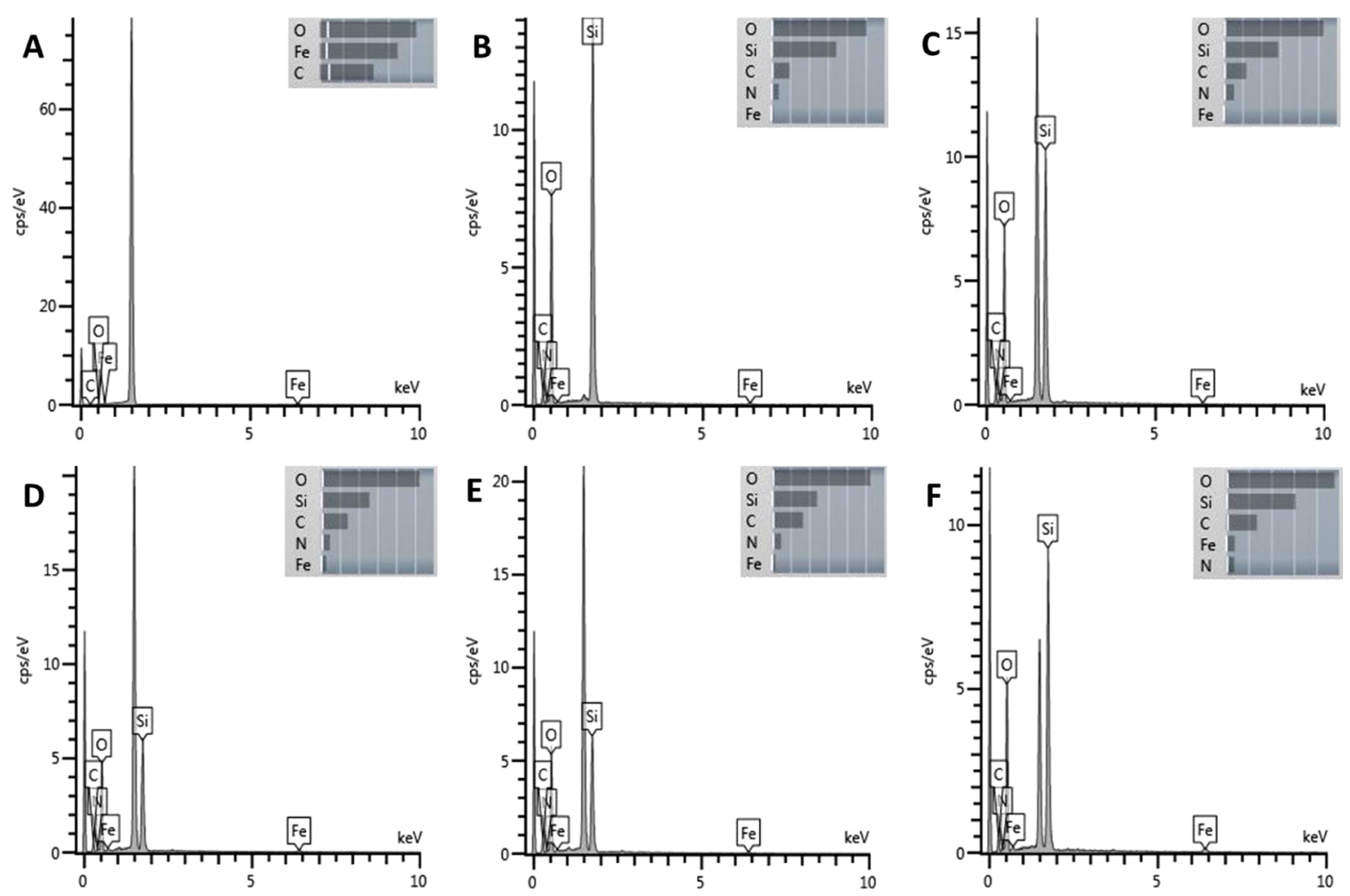

Figure 7. EDX spectra of (a) $\mathrm{Fe}_{3} \mathrm{O}_{4}$, (b) $\mathrm{Fe}_{3} \mathrm{O}_{4} @ \mathrm{SiO}_{2}$ (FITC), (c) $\mathrm{Fe}_{3} \mathrm{O}_{4} @ \mathrm{SiO}_{2}$ (FITC)-FA/ $\mathrm{NH}_{2}$, (d) $\mathrm{Fe}_{3} \mathrm{O}_{4} @ \mathrm{SiO}_{2}(\mathrm{FITC})-\mathrm{FA} / \mathrm{AICAR}$, (e) $\mathrm{Fe}_{3} \mathrm{O}_{4} @ \mathrm{SiO}_{2}$ (FITC)-FA/DOX, and (f) $\mathrm{Fe}_{3} \mathrm{O}_{4} @ \mathrm{SiO}_{2}$ (FITC)-FA/AICAR/DOX nanoparticles (inset: weight percentages of composition), obtained during SEM experiments.

in oleic acid, confirm the presence of the oleic acid on the $\mathrm{Fe}_{3} \mathrm{O}_{4}$ surface. ${ }^{29}$ The spectrum of $\mathrm{Fe}_{3} \mathrm{O}_{4}$ nanoparticles exhibited a strong peak at $584 \mathrm{~cm}^{-1}$ which is assigned to typical $\mathrm{Fe}-\mathrm{O}$ vibrations of the magnetite structure, sustaining the iron oxide identification by XRD. ${ }^{30}$

In the FTIR spectra of $\mathrm{Fe}_{3} \mathrm{O}_{4} @ \mathrm{SiO}_{2}$ (FITC), new bands associated with $\mathrm{Si}-\mathrm{O}-\mathrm{Si}$ asymmetric stretching at $1070 \mathrm{~cm}^{-1}$, $\mathrm{Si}-\mathrm{OH}$ stretching at $950 \mathrm{~cm}^{-1}, \mathrm{Si}-\mathrm{O}-\mathrm{Si}$ symmetric stretching at $794 \mathrm{~cm}^{-1}$, and $\mathrm{Si}-\mathrm{O}-\mathrm{Si}$ bending vibrations at $467 \mathrm{~cm}^{-1}$ were observed, thus confirming the formation of the silica shells. ${ }^{31}$ The broad band around $3425 \mathrm{~cm}^{-1}$ was due to $\mathrm{O}-\mathrm{H}$ stretching vibrations of adsorbed water and hydrogen-bonded surface silanol groups, whereas the bands around 1548 and $1632 \mathrm{~cm}^{-1}$ are attributed to bending of $\mathrm{N}-\mathrm{H}$, characteristic of the presence of an $\mathrm{NH}_{2}$ group. ${ }^{32}$ Furthermore, a significant decrease in the intensity of the bands related to $\mathrm{Fe}-\mathrm{O}$ vibrations at $580 \mathrm{~cm}^{-1}$, revealing an increase in the thickness of the silica shells and the complete encapsulation of the magnetic cores, in accordance with the results from XRD and EDX.

The band at $1606 \mathrm{~cm}^{-1}$ corresponding to the stretching vibrations of $\mathrm{C}=\mathrm{C}$ in the backbone of the aromatic ring present in folic acid, indicated the immobilization of folic acid on nanoparticle surfaces. The peak at $1534 \mathrm{~cm}^{-1}$ is due to the primary amine group of APTES, indicating that the nanoparticles have been surface modified by amine group. The band at $1585 \mathrm{~cm}^{-1}$, referred to as the stretching vibration of two carbonyl groups of the anthracene ring of $\mathrm{DOX}^{33}$ indicated that DOX was successfully attached to the surface of the nanoparticles. The spectral range between 1000 and $800 \mathrm{~cm}^{-1}$ is very informative on nucleic acid absorption, due to sugar vibrations sensitive to their conformation and to backbone vibrational modes. Therefore, the bands at 890 and $926 \mathrm{~cm}^{-1}$ indicated that AICAR immobilization with covalent bonding on the surface of the nanoparticles was successfully achieved. ${ }^{34}$

The grafting density of FA, AICAR, and DOX on nanoparticles was analyzed by measuring the differences of weight loss due to organics decomposition in both $\mathrm{Fe}_{3} \mathrm{O}_{4} @ \mathrm{SiO}_{2}$ (FITC) and $\mathrm{Fe}_{3} \mathrm{O}_{4} @ \mathrm{SiO}_{2}$ (FITC)-FA/AICAR/DOX nanoparticles, by TGA (Figure 5). According to the results, the decreased weight of $\mathrm{Fe}_{3} \mathrm{O}_{4} @ \mathrm{SiO}_{2}$ (FITC) nanoparticles was about $7.77 \%$ between 25 and $650{ }^{\circ} \mathrm{C}$, presumably due to the degradation of the organic fluorescent FITC within silica layer. $\mathrm{Fe}_{3} \mathrm{O}_{4} @ \mathrm{SiO}_{2}(\mathrm{FITC})-\mathrm{FA} /$ AICAR/DOX nanoparticles showed a weight loss of $21.20 \mathrm{wt} \%$ and exhibited a four-stage weight loss process in the same temperature range, which could be attributed to the presence of substantial amount of FA, AICAR, and DOX molecules. The notable difference ( $13.43 \mathrm{wt} \%$ ) between the mass loss of $\mathrm{Fe}_{3} \mathrm{O}_{4} @ \mathrm{SiO}_{2}$ (FITC) and $\mathrm{Fe}_{3} \mathrm{O}_{4} @ \mathrm{SiO}_{2}$ (FITC)-FA/AICAR/ DOX nanoparticles revealed the successful surface conjugation of the nanoparticles with FA, AICAR, and DOX.

The exterior morphologies and interior structures of the nanoparticles at different fabrication stage were investigated by SEM and STEM, respectively; and the related chemical compositions were determined by EDX.

SEM images showed that the parent iron oxide nanoparticles were nearly spherical and present a narrow size distribution (Figure $6 \mathrm{a} / \mathrm{b} / \mathrm{c}$ ). The corresponding EDX spectrum confirmed that the $\mathrm{Fe}_{3} \mathrm{O}_{4}$ particles are composed of $\mathrm{Fe}$ and $\mathrm{O}$, with the $\mathrm{C}$ peak indicating the presence of a thin oleic acid shell enveloping the magnetic cores, without any impurity. The untagged $\mathrm{Al}$ peak is from the double stick aluminum tape used in sample preparation (Figure $7 \mathrm{a}$ and Table 3 ). After the silica coating, $\mathrm{Fe}_{3} \mathrm{O}_{4} @ \mathrm{SiO}_{2}\left(\right.$ FITC) and $\mathrm{Fe}_{3} \mathrm{O}_{4} @ \mathrm{SiO}_{2}\left(\right.$ FITC)-FA/ $\mathrm{NH}_{2}$ nanoparticle morphology remained unchanged. EDX analysis 
Table 3. Surface Atomic Percentages of the Nanoparticles, Obtained from EDX Spectra

\begin{tabular}{lccccc} 
& \multicolumn{5}{c}{ atomic (\%) } \\
\cline { 2 - 6 } \multicolumn{1}{c}{ nanoparticles } & $\mathrm{O}$ & $\mathrm{Si}$ & $\mathrm{C}$ & $\mathrm{N}$ & $\mathrm{Fe}$ \\
$\mathrm{Fe}_{3} \mathrm{O}_{4}$ & 51.6 & - & 37.4 & - & 11.0 \\
$\mathrm{Fe}_{3} \mathrm{O}_{4} @ \mathrm{SiO}_{2}$ (FITC) & 56.9 & 22.4 & 15.1 & 5.1 & 0.5 \\
$\mathrm{Fe}_{3} \mathrm{O}_{4} @ \mathrm{SiO}_{2}$ (FITC)-FA/NH & 57.5 & 17.9 & 17.4 & 6.9 & 0.3 \\
$\mathrm{Fe}_{3} \mathrm{O}_{4} @ \mathrm{SiO}_{2}$ (FITC)-FA/AICAR & 56.1 & 13.1 & 26.3 & 3.8 & 0.7 \\
$\mathrm{Fe}_{3} \mathrm{O}_{4} @ \mathrm{SiO}_{2}$ (FITC)-FA/DOX & 53.7 & 14.6 & 25.8 & 5.2 & 0.7 \\
$\mathrm{Fe}_{3} \mathrm{O}_{4} @ \mathrm{SiO}_{2}$ (FITC)-FA/AICAR/DOX & 55.5 & 14.7 & 25.5 & 3.5 & 0.8 \\
\hline
\end{tabular}

confirmed the existence of $\mathrm{Si}$, a gradual increase in the $\mathrm{N}$ content, and a significant decrease in the Fe content, which was still detected due to the penetration depth of the X-ray beam, thus confirming the encapsulation of the magnetic cores in a thick silica shell (Figure 7b/c). The EDX analysis of $\mathrm{Fe}_{3} \mathrm{O}_{4} @$ $\mathrm{SiO}_{2}$ (FITC)-FA/AICAR, $\mathrm{Fe}_{3} \mathrm{O}_{4} @ \mathrm{SiO}_{2}$ (FITC)-FA/DOX, and $\mathrm{Fe}_{3} \mathrm{O}_{4} @ \mathrm{SiO}_{2}$ (FITC)-FA/AICAR/DOX nanoparticles clearly showed the progressive increase in $\mathrm{C}$ content and reduction in $\mathrm{N}$ content on the silica surfaces due to organic functionalities which are gradually enriched by iterative chemical conjugation (Figure $7 \mathrm{~d} / \mathrm{e} / \mathrm{f}$ ).

The morphologies of the $\mathrm{Fe}_{3} \mathrm{O}_{4} @ \mathrm{SiO}_{2}$ (FITC)-FA/AICAR, $\mathrm{Fe}_{3} \mathrm{O}_{4} @ \mathrm{SiO}_{2}$ (FITC)-FA/DOX, and $\mathrm{Fe}_{3} \mathrm{O}_{4} @ \mathrm{SiO}_{2}$ (FITC)-FA/ AICAR/DOX nanoparticles were investigated by STEM. Figure $6 \mathrm{~d} / \mathrm{e} / \mathrm{f}$ shows that the nanoparticles have core-shell morphology and spherical shape without aggregation or accumulation.

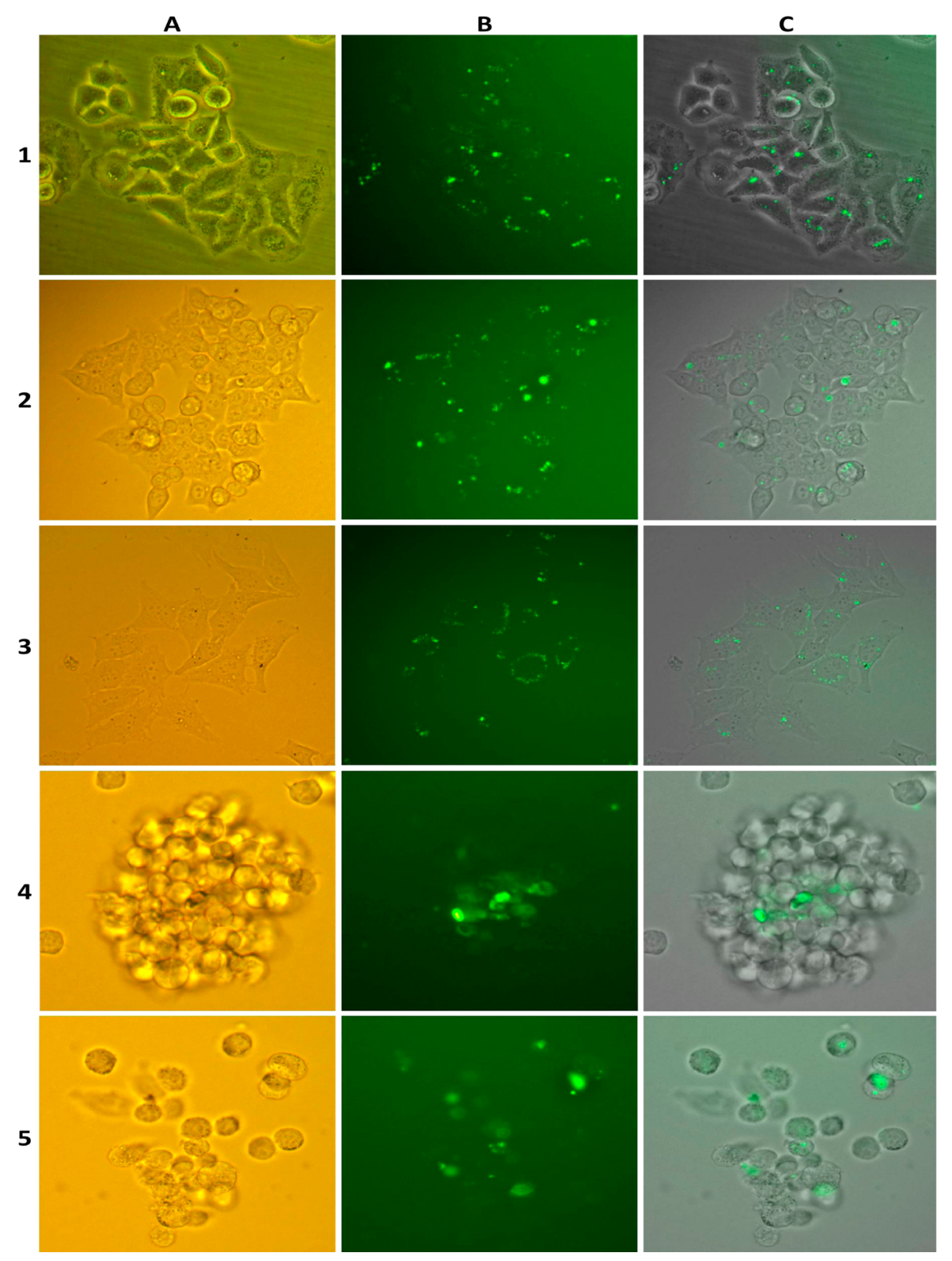

Figure 8. Intracellular localization of the $\mathrm{Fe}_{3} \mathrm{O}_{4} @ \mathrm{SiO}_{2}$ (FITC)-FA/AICAR/DOX nanoparticles in cancer cells. For rows: A, bright-field images; B, fluorescence images; C, the merger of both. For columns: 1, A549; 2, HCT-116; 3, HeLa; 4, Jurkat; and 5, MIA PaCa-2 cells. 
Table 4. $\mathrm{IC}_{50}$ values of $\mathrm{Fe}_{3} \mathrm{O}_{4} @ \mathrm{SiO}_{2}$ (FITC)-FA, $\mathrm{Fe}_{3} \mathrm{O}_{4} @ \mathrm{SiO}_{2}\left(\right.$ FITC)-FA/AICAR, $\mathrm{Fe}_{3} \mathrm{O}_{4} @ \mathrm{SiO}_{2}(\mathrm{FITC})-\mathrm{FA} / \mathrm{DOX}$, and $\mathrm{Fe}_{3} \mathrm{O}_{4} @ \mathrm{SiO}_{2}$ (FITC)-FA/AICAR/DOX Nanoparticles in A549, HCT-116, HeLa, Jurkat, and MIA PaCa-2 Cells When Incubated for $48 \mathrm{~h}^{a}$

\begin{tabular}{lllllc}
\multicolumn{1}{c}{ nanoparticles $(\mu \mathrm{g} / \mathrm{mL})$} & \multicolumn{1}{c}{ A549 } & HCT-116 & \multicolumn{1}{c}{ HeLa } & Jurkat & MIA PaCa-2 \\
$\mathrm{Fe}_{3} \mathrm{O}_{4} @ \mathrm{SiO}_{2}$ (FITC)-FA & N.A. & N.A. & N.A. & N.A. & N.A. \\
$\mathrm{Fe}_{3} \mathrm{O}_{4} @ \mathrm{SiO}_{2}$ (FITC)-FA/AICAR & N.A. & N.A. & N.A. & N.A. & N.A. \\
$\mathrm{Fe}_{3} \mathrm{O}_{4} @ \mathrm{SiO}_{2}$ (FITC)-FA/DOX & $26.4 \pm 1.4$ & $48.0 \pm 4.8$ & $61.2 \pm 6.1$ & $41.7 \pm 2.9$ & $48.7 \pm 3.8$ \\
$\mathrm{Fe}_{3} \mathrm{O}_{4} @ \mathrm{SiO}_{2}$ (FITC)-FA/AICAR/DOX & $14.8 \pm 4.1$ & $49.5 \pm 3.0$ & $47.5 \pm 2.5$ & $48.2 \pm 3.1$ & $58.0 \pm 5.2$
\end{tabular}

${ }^{a}$ N.A. $=$ Not Applicable (the data cannot be fitted as no enough inhibition is observed) in the cancer cells. Values represent the mean \pm SD of three independent experiments.

Cellular Uptake. Specificity and cellular accumulation of $\mathrm{Fe}_{3} \mathrm{O}_{4} @ \mathrm{SiO}_{2}$ (FITC)-FA/AICAR/DOX nanoparticle vectors by five tumor-derived cell lines (A549, HCT-116, HeLa, Jurkat, and MIA PaCa-2) were confirmed by fluorescence microscopy, which demonstrated intracellular nanoparticle accumulations in each cell line (Figure 8 plots $1-5$, rows $a-c$ ). The weak green fluorescence in the cytoplasm clearly indicated the successful penetration of the vectors into the cells via folate-receptormediated endocytosis. Verification of cellular accumulation of the vectors was obtained by comparing of the fluorescence images with the corresponding bright-field images. The overlay images demonstrated that the magnetic-fluorescent vectors represent a true molecular targeting. These results corroborated the overexpression of folate receptor on A549, HCT-116, HeLa, Jurkat, and MIA PaCa- 2 cells, which facilitate the recognition of nanoparticles and increase the uptake through internalization. ${ }^{35}$

Cytotoxicity of the Multifunctional Nanoparticles. To examine how the conjugation of AICAR with DOX affected its cytotoxicity, we compared the proliferation of A549, HCT-116, HeLa, Jurkat, and MIA PaCa-2 cells treated with the nanoparticle complexes using MTT cell proliferation assay. First, we chose a concentration of DOX $(20 \mu \mathrm{M}) 10$ times lower than the concentration of $\operatorname{AICAR}(200 \mu \mathrm{M})$ during immobilization processes in terms of minimal growth inhibition in these cells for our combination therapy studies. Next, we investigated whether combination therapy with the inhibitor and drug would be effective at inhibiting tumor cell proliferation and inducing cell death. Cancer cells were exposed to nanoparticles with increasing concentrations of nanoparticles $(0.1-200 \mu \mathrm{g} / \mathrm{mL})$ for $48 \mathrm{~h}$. Among all nanoparticles tested, $\mathrm{Fe}_{3} \mathrm{O}_{4} @ \mathrm{SiO}_{2}$ (FITC)-FA/AICAR/DOX nanoparticles showed the lowest $\mathrm{IC}_{50}$ value in $\mathrm{A} 549$ cells and led to approximately 1.8-fold decreases in the $\mathrm{IC}_{50}$ values to $\mathrm{Fe}_{3} \mathrm{O}_{4} @ \mathrm{SiO}_{2}$ (FITC)FA/DOX nanoparticles that would be significant in a clinical context (Table 4). The conjugation of AICAR with DOX improved the cytotoxicity not only with a synergistic inhibition, but also with a $30 \%$ decreased level of DOX in $\mathrm{Fe}_{3} \mathrm{O}_{4} @$ $\mathrm{SiO}_{2}$ (FITC)-FA/AICAR/DOX nanoparticles. $\mathrm{Fe}_{3} \mathrm{O}_{4} @$ $\mathrm{SiO}_{2}$ (FITC)-FA/AICAR nanoparticles showed low cytotoxicity to all the cells tested, whereas $\mathrm{Fe}_{3} \mathrm{O}_{4} @ \mathrm{SiO}_{2}$ (FITC)-FA control nanoparticles did not affect cancer cell viabilities to the same extent (Figure 9). These data showed that $\mathrm{Fe}_{3} \mathrm{O}_{4} @ \mathrm{SiO}_{2}$ (FITC)FA/AICAR/DOX nanoparticles were more effective against A549 and HeLa cells while HCT-116, Jurkat, and MIA PaCa-2 had similar $\mathrm{IC}_{50}$ values. These results indicate that survivin inhibition by AICAR can increase the efficacy of chemotherapy for a wide range of cancer types, which may have important implications for the design of experimental protocols.

We also observed a clear dose-dependent inhibition with $\mathrm{Fe}_{3} \mathrm{O}_{4} @ \mathrm{SiO}_{2}$ (FITC)-FA/AICAR/DOX and $\mathrm{Fe}_{3} \mathrm{O}_{4} @$ $\mathrm{SiO}_{2}$ (FITC)-FA/DOX nanoparticles in all the cancer cells tested. These nanoparticles strongly reduced the proliferation of cancer cells after $48 \mathrm{~h}$ of treatment, while a low effect was observed with $\mathrm{Fe}_{3} \mathrm{O}_{4} @ \mathrm{SiO}_{2}$ (FITC)-FA/AICAR nanoparticles and no significant effect of the control $\mathrm{Fe}_{3} \mathrm{O}_{4} @ \mathrm{SiO}_{2}$ (FITC)-FA nanoparticles. The poor antitumoral efficacy exhibited by $\mathrm{Fe}_{3} \mathrm{O}_{4} @ \mathrm{SiO}_{2}$ (FITC)-FA/AICAR indicates that the maximum amount of these nanoparticles in the cells was not sufficient to affect cell viability. This implies that a higher concentration of the nanoparticles would be needed to obtain a notable reduction in cell viability.

As survivin is not a cell surface protein and does not have an intrinsic enzymatic activity, targeting of survivin for therapeutic purposes has been mostly employed at the transcriptional levels. ${ }^{6}$ A number of siRNA-based therapies have been reported as survivin neutralizing agent to increase the sensitivity of cancer cells to DOX and have managed to restore sensitivity to chemotherapeutically induced apoptosis in several cancer cells. ${ }^{36,37}$ However, one of the main hurdles to the application of siRNA-based therapy identified to date is the potential offtarget effects. It has been well-documented that delivering siRNA into cells can suppress the expression of genes other than the desired targets. ${ }^{38}$ To eliminate these obstacles, AICAR could be of potential value for increasing the sensitivity of cancer cells to anticancer drugs, as a small-molecule inhibitor that could be easily incorporated in practice for the downregulation of survivin.

\section{CONCLUSIONS}

Herein we presented successful fabrication and characterization of novel magnetic-fluorescence based, folic acid functionalized nanoparticles for simultaneous delivery of AICAR and DOX into cancer cells. These multifunctional nanoparticles were synthesized by a simple coprecipitation of $\mathrm{Fe}^{2+} / \mathrm{Fe}^{3+}$ salts which

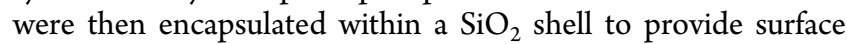
modification and biocompatibility as well as to act as a host for fluorescent dye (FITC). The cancer targeting feature was endowed by conjugating FA on the surface of nanoparticles via an esterification reaction. AICAR and DOX complexes were then successfully attached on the amine-functionalized nanoparticles using Schiff-base chemistry. As far as we know, the synergetic effect of AICAR and DOX has not yet been investigated and this is the first successful preparation of AICAR-DOX conjugated luminomagnetic nanoparticles as a single platform. The structures of the newly synthesized nanoparticles have been confirmed by different characterization techniques: DLS; XRD; FTIR; TGA; EDX; SEM; and STEM. The nanoparticles possess high inhibitor and drug association with good biocompatibility. In addition, the preparation procedure is an environmentally friendly and low-cost synthetic route.

The combination of AICAR and DOX is expected to maximize tumor cell killing by sensitization of cancer cells and 

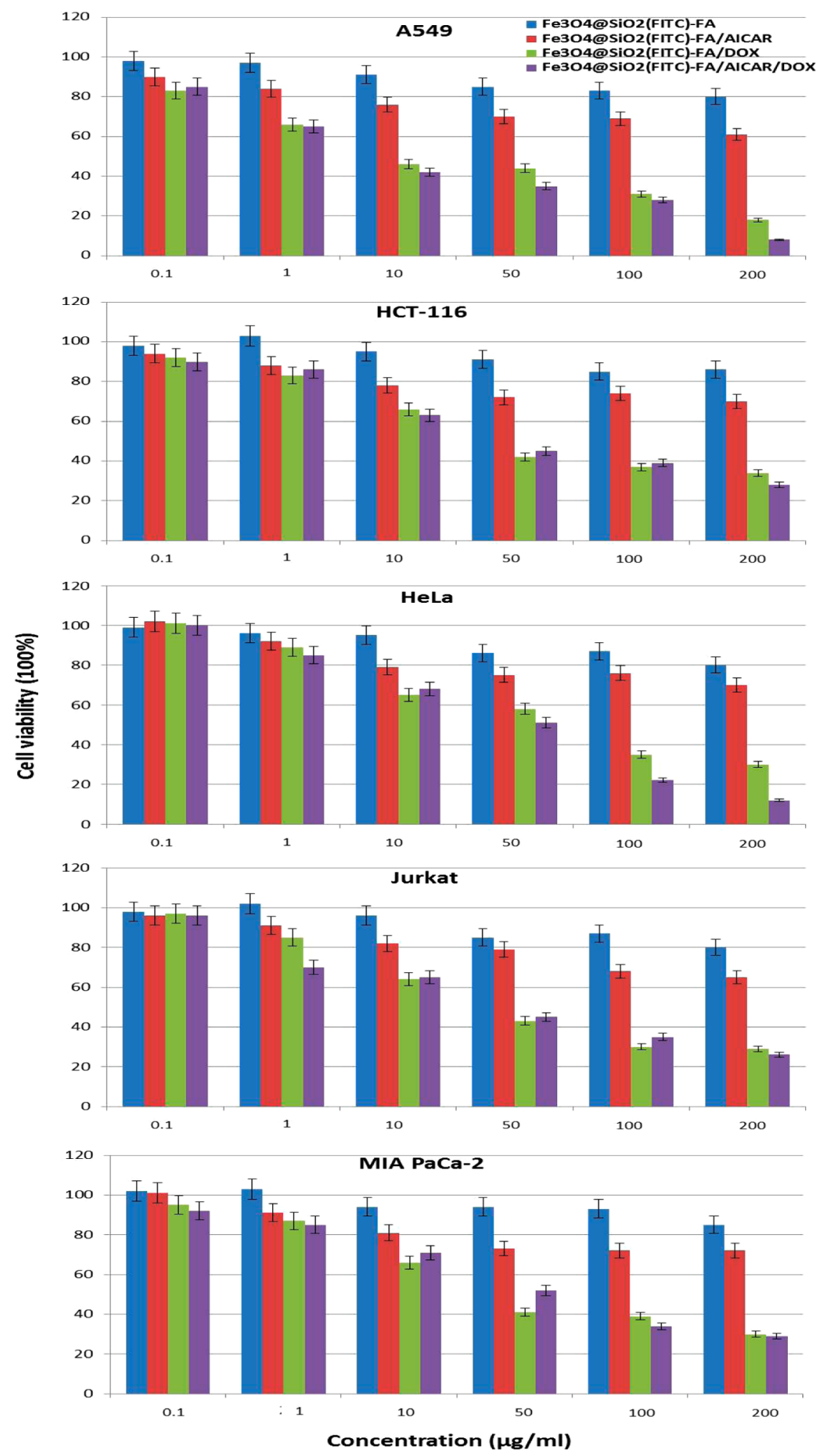

Figure 9. Anticancer activities of $\mathrm{Fe}_{3} \mathrm{O}_{4} @ \mathrm{SiO}_{2}(\mathrm{FITC})-\mathrm{FA}, \mathrm{Fe}_{3} \mathrm{O}_{4} @ \mathrm{SiO}_{2}(\mathrm{FITC})-\mathrm{FA} / \mathrm{AICAR}, \mathrm{Fe}_{3} \mathrm{O}_{4} @ \mathrm{SiO}_{2}(\mathrm{FITC})-\mathrm{FA} / \mathrm{DOX}$, and $\mathrm{Fe} \mathrm{O}_{4} @$ $\mathrm{SiO}_{2}$ (FITC)-FA/AICAR/DOX nanoparticles against A549, HCT-116, HeLa, Jurkat, and MIA PaCa-2 cells after 48 h of growth. The results are expressed as percentage of cell viability or cell number obtained in the untreated controls. The nanoparticle concentrations are expressed as $\mu \mathrm{g}$ nanoparticles per mL. $\mathrm{Fe}_{3} \mathrm{O}_{4} @ \mathrm{SiO}_{2}$ (FITC)-FA blank nanoparticles were used as control. Each column represents the mean \pm SD of three independent experiments performed in triplicate normalized to nontreated cells (taken as 100\%). Note that the amount of DOX conjugation on the surface of $\mathrm{Fe}_{3} \mathrm{O}_{4} @ \mathrm{SiO}_{2}$ (FITC)-FA/AICAR/DOX nanoparticles is 30\% less than the surface of $\mathrm{Fe}_{3} \mathrm{O}_{4} @ \mathrm{SiO}_{2}$ (FITC)-FA/DOX nanoparticles.

to minimize organ toxicity by targeting administration of the inhibitor and drug complex. Fluorescence microscopy and MTT studies confirmed intracellular nanoparticle accumulation and efficient antitumor activity. We have shown that the cancer cells can be visualized with a low concentration of $\mathrm{Fe}_{3} \mathrm{O}_{4} @$ $\mathrm{SiO}_{2}$ (FITC)-FA/AICAR/DOX nanoparticles $(10 \mu \mathrm{g} / \mathrm{mL})$ with 
detectable cell numbers about $10^{5}$ confirming cellular uptake of nanoparticles. Moreover, the nanoparticles not only served as a nanocarrier but also exhibited synergistic cytotoxic activity against the cancer cells. We have demonstrated that combination therapy with $\mathrm{Fe}_{3} \mathrm{O}_{4} @ \mathrm{SiO}_{2}$ (FITC)-FA/AICAR/ DOX nanoparticles is superior to monotherapy with nanoparticles decorated with either AICAR or DOX alone. Importantly, the combination effects of the nanoparticles were confirmed in five different cancer cell lines. Our data indicate a strong effect of $\mathrm{Fe}_{3} \mathrm{O}_{4} @ \mathrm{SiO}_{2}$ (FITC)-FA/AICAR/ DOX nanoparticles on the lung carcinoma A549 and the cervical carcinoma HeLa cell lines, while similar outcomes were observed on the colon carcinoma HCT-116, the leukemia Jurkat, and the pancreatic carcinoma MIA PaCa-2 cell lines. We believe that this combination will be a valuable addition in the sensitization of cancer cells toward anticancer drugs to improve the therapeutic outcome of chemotherapy. Finally, it could be concluded that coadministration of AICAR and DOX might promote apoptosis more than each drug alone or incubation of one compound prior to the other one. The characterization of apoptotic and antiproliferative effects and related caspase- 3 activity studies of the nanoparticles are currently under investigation.

\section{MATERIAL AND METHODS}

Materials. Iron(II) chloride tetrahydrate $\left(\mathrm{FeCl}_{2} \cdot 4 \mathrm{H}_{2} \mathrm{O}\right)$ (99\%), iron(III) chloride hexahydrate $\left(\mathrm{FeCl}_{3} \cdot 6 \mathrm{H}_{2} \mathrm{O}\right)(98 \%)$, 3-aminopropyltriethoxysilane (APTES), tetraethyl orthosilicate 99.9\% (TEOS), N-hydroxysuccinimide (NHS), N,N-dicyclohexyl-carbodiimide (DCC), fluorescein isothiocyanate (FITC), folic acid (FA), dimethyl sulfoxide (DMSO), triton X-100, FTIR grade potassium bromide $\geq 99 \%$ ( $\mathrm{KBr}$ ), Glutaraldehyde $25 \%$ aqueous solution, 5-aminoimidazole-4-carboxamide-1- $\beta$-D-ribofuranoside $\geq 98 \%$ (AICAR), and 3-[4,5-dimethyl-2-thialzolyl]2,5-diphenyltetrazolium bromide (MTT) were purchased from Sigma-Aldrich Chemicals. Oleic acid (99\%), cyclohexane, 1-hexanol (>98\%), ammonium hydroxide $25 \%$ aqueous solution, and toluene were purchased from Fluka/Riedel-de Haën Chemicals. Doxorubicin was obtained from SABA Pharma. DMEM growth medium, RPMI-1640 growth medium, $10 \%$ fetal bovine serum (FBS), streptomycin, penicillin, and L-glutamic acid were purchased from Gibco Life Technologies. All other chemicals and reagents were of the highest purity. All the experiments were performed in deionized Milli-Q water.

Cell Cultures. A549 (human epithelial lung carcinoma), HCT-116 (human epithelial colorectal carcinoma), HeLa (human epithelial cervical carcinoma), Jurkat (human acute T-cell leukemia), and MIA PaCa-2 (human epithelial pancreatic carcinoma) cell lines were kindly provided by Biotechnology and Bioengineering Research and Application Centre, Izmir Institute of Technology, Turkey. A549, HCT-116, HeLa, and MIA PaCa-2 cancer cells were cultured in Dulbecco's modified Eagle medium (DMEM) supplemented with $10 \%$ fetal bovine serum (FBS), $100 \mu \mathrm{g} / \mathrm{mL}$ streptomycin, $100 \mathrm{U} / \mathrm{mL}$ penicillin, and $2 \mathrm{mM}$ L-glutamic acid; Jurkat cancer cells were cultured in Roswell Park Memorial Institute-1640 (RPMI-1640) growth medium supplemented with $10 \%$ fetal bovine serum (FBS), $100 \mu \mathrm{g} / \mathrm{mL}$ streptomycin, $100 \mathrm{U} / \mathrm{mL}$ penicillin, and $2 \mathrm{mM}$ L-glutamic acid. All cell lines were incubated in $5 \% \mathrm{CO}_{2}$ and $90-100 \%$ relative humidity at $37{ }^{\circ} \mathrm{C}$. Medium renewal was carried out 2 to 3 times per week, and cells were subcultured when they achieved $80-90 \%$ confluence. All cell lines were discarded after 20 generations, and new lines were obtained from frozen stocks.

Synthesis of Multifunctional Nanoparticles. Synthesis of Oleic Acid Coated $\mathrm{Fe}_{3} \mathrm{O}_{4}$ Nanoparticles. Oleic acid coated iron oxide $\left(\mathrm{Fe}_{3} \mathrm{O}_{4}\right)$ nanoparticles were synthesized by coprecipitation of $\mathrm{Fe}^{2+}$ and $\mathrm{Fe}^{3+}$ salts with a stoichiometric ratio of $1: 2$ in accordance with the chemical reaction formula: $\left[\mathrm{Fe}^{2+}+2 \mathrm{Fe}^{+3}+8 \mathrm{OH}^{-}=\mathrm{Fe}_{3} \mathrm{O}_{4}+4 \mathrm{H}_{2} \mathrm{O}\right]$. Since oleic acid effectively regulates $\mathrm{Fe}_{3} \mathrm{O}_{4}$ nanoparticles growth and prevents aggregation, ${ }^{20}$ in this step we determined the oleic acid concentration to obtain surfactant-stabilized and narrow size distributed $\mathrm{Fe}_{3} \mathrm{O}_{4}$ nanoparticles. First, $0.456 \mathrm{~g} \mathrm{FeCl}_{3} \cdot 6 \mathrm{H}_{2} \mathrm{O}$ and $0.189 \mathrm{~g} \mathrm{FeCl}_{2} \cdot 4 \mathrm{H}_{2} \mathrm{O}$ were dissolved in $100 \mathrm{~mL}$ ultrapure water under nitrogen environment with ultrasonification for $10 \mathrm{~min}$. $\mathrm{NH}_{4} \mathrm{OH}(25 \%)$ aqueous solution was added dropwise until $\mathrm{pH}$ 10-11. After base had been added, the alkaline solution started to became dark brown. Oleic acid (0.1/0.2/0.4/0.6 mL) was added immediately to the dark brown solution and the resulting emulsion was aged, under vigorous mechanical stirring, at room temperature for $1 \mathrm{~h}$. Then the emulsion was heated up to $95{ }^{\circ} \mathrm{C}$ to convert iron hydroxides into magnetite. As soon as that temperature was reached, the suspension was cooled down to room temperature. The mixture was then acidified to $\mathrm{pH} 5-6$ by using a $\mathrm{HNO}_{3}$ solution (35\%) to promote the chemisorption of oleate ions on the magnetite particles. Consequently, the particles coagulated and precipitated in the solution due to the hydrophobicity provided by the oleate layer. The resulting magnetic particles settled within a few minutes and were then washed with ultrapure water four times to remove the unreacted salts and with ethanol three times to remove water and nonadsorbed oleic acid. Finally, the oleic acid coated nanoparticles were dried in vacuum oven at room temperature for $12 \mathrm{~h}$.

Synthesis of $\mathrm{Fe}_{3} \mathrm{O}_{4} @ \mathrm{SiO}_{2}$ (FITC) Nanoparticles. Silica coreshell nanoparticles $\left[\mathrm{Fe}_{3} \mathrm{O}_{4} @ \mathrm{SiO}_{2}(\right.$ FITC) $]$ were synthesized by a water-in-oil reverse micelle method with some modification of a published procedure in two steps. ${ }^{21}$ In the first step, the oleic acid protected $\mathrm{Fe}_{3} \mathrm{O}_{4}$ nanoparticles were coated with a thin silica shell by hydrolysis and condensation of TEOS as sol-gel precursor. Briefly, a microemulsion system was prepared with $10 \mathrm{mg}$ of dried magnetic $\mathrm{Fe}_{3} \mathrm{O}_{4}$ powder added to $0.3 \mathrm{~mL}$ TEOS, $70 \mathrm{~mL}$ cyclohexane, $20 \mathrm{~g}$ Triton X-100 (as surfactant), $15 \mathrm{~mL} n$-hexanol (as cosurfactant), and $3.7 \mathrm{~mL} \mathrm{H}_{2} \mathrm{O}$ mixture with intense stirring at room temperature. Six hours later, $1.0 \mathrm{~mL}$ aqueous $\mathrm{NH}_{4} \mathrm{OH}(25 \%)$ was introduced dropwise to initiate TEOS hydrolysis and the microemulsion was kept stirring for another $24 \mathrm{~h}$. In the second step, after the first silica shell had been coated on the magnetic core, the dye molecules were encapsulated into the second silica shell to enhance photochemical stability. FITC-APTES conjugate was prepared by covalently attaching FITC to the APTES silane compound by a stable thiourea linkage. Briefly, $1.0 \mathrm{mg}$ FITC and $0.15 \mathrm{~mL}$ APTES were combined together in $0.2 \mathrm{~mL}$ of absolute ethanol under nitrogen atmosphere and stirred in orbital shaker for $24 \mathrm{~h}$. The FITC-APTES conjugate solution was protected from light during reaction and storage to prevent photobleaching. After $24 \mathrm{~h}$, FITC-APTES ethanolic solution and $0.3 \mathrm{~mL}$ TEOS were added to the first microemulsion under stirring in dark for 24 h. Finally, ethanol was added to destabilize the microemulsion system. The FITC-incorporated silica-coated coreshell $\left[\mathrm{Fe}_{3} \mathrm{O}_{4} @ \mathrm{SiO}_{2}(\mathrm{FITC})\right]$ nanoparticles were collected via centrifugation and washed in sequence with ethanol and 
ultrapure water to remove any surfactant and unreacted reactants and dried by air.

Synthesis of $\mathrm{Fe}_{3} \mathrm{O}_{4} @ \mathrm{SiO}_{2}$ (FITC)-FA/NH $\mathrm{N}_{2}$ Nanoparticles. The $\mathrm{Fe}_{3} \mathrm{O}_{4} @ \mathrm{SiO}_{2}$ (FITC)-FA/ $\mathrm{NH}_{2}$ nanoparticles were prepared according to a literature procedure with some modification. ${ }^{22}$ First, folic acid was conjugated with APTES by an esterification reaction of the carboxyl group with the amine group. In brief, an APTES ester of FA (FA-APTES) was prepared by mixing folate $(4.0 \mathrm{mg})$ with APTES $(2.0 \mu \mathrm{L})$ in $40 \mathrm{~mL}$ dry dimethyl sulfoxide (DMSO) in the presence of NHS $(1.1 \mathrm{mg})$ and DCC $(4.7 \mathrm{mg})$ as the catalyst at room temperature for $2 \mathrm{~h}$. After this, a mixture of $\mathrm{Fe}_{3} \mathrm{O}_{4} @ \mathrm{SiO}_{2}$ (FITC) nanoparticles (100 mg), FA-APTES conjugate, and free APTES $(17 \mu \mathrm{L})$ in toluene $(160 \mathrm{~mL})$ was stirred at room temperature for $24 \mathrm{~h}$ to introduce FA-APTES conjugate and free APTES (to provide a linker for the subsequent conjugation of both AICAR and DOX) on the surface of silica-coated nanoparticles by hydrolysis and condensation of APTES through silanization. Final products were collected by a magnet, washed with toluene and ethanol several times to remove any unreacted reactants, and dried in a vacuum oven at room temperature, overnight.

Synthesis of $\mathrm{Fe}_{3} \mathrm{O}_{4} @ \mathrm{SiO}_{2}$ (FITC)-FA/AICAR/DOX Nanoparticles. $\mathrm{Fe}_{3} \mathrm{O}_{4} @ \mathrm{SiO}_{2}$ (FITC)-FA/AICAR/DOX were prepared by coupling of AICAR and DOX complexes on the surface of amine-modified nanoparticles via glutaraldehyde activation. In this step three successive nanoparticles were synthesized to evaluate the synergistic potential of therapeutics: (1) $\mathrm{Fe}_{3} \mathrm{O}_{4} @$ $\mathrm{SiO}_{2}$ (FITC)-FA/AICAR nanoparticles containing only inhibitor; (2) $\mathrm{Fe}_{3} \mathrm{O}_{4} @ \mathrm{SiO}_{2}$ (FITC)-FA/DOX nanoparticles containing only drug; (3) $\mathrm{Fe}_{3} \mathrm{O}_{4} @ \mathrm{SiO}_{2}$ (FITC)-FA/AICAR/DOX nanoparticles containing both inhibitor and drug. Furthermore, since glutaraldehyde is a very reactive reagent, ${ }^{23}$ different concentrations of glutaraldehyde were tested separately to determine the optimal linker concentration. First of all, the surface of $\mathrm{Fe}_{3} \mathrm{O}_{4} @ \mathrm{SiO}_{2}$ (FITC)-FA/ $\mathrm{NH}_{2}$ nanoparticles $(10 \mathrm{mg}$ ) was activated with glutaraldehyde $(0.1-1.0 \%)$ in $20 \mathrm{~mL}$ ultrapure water under vigorous mechanical stirring at room temperature for $30 \mathrm{~min}$. Then, nanoparticles were collected via centrifugation and the unreacted glutaraldehyde was removed by comprehensive washing with ultrapure water. Glutaraldehyde activated nanoparticles were subsequently incubated with $\operatorname{AICAR}(200 \mu \mathrm{M})$ and DOX $(20 \mu \mathrm{M})$ complexes in $20 \mathrm{~mL}$ ultrapure water under vigorous mechanical stirring at room temperature for $6 \mathrm{~h}$. For AICAR and DOX conjugation, an excess amount of AICAR (molar ratio of AICAR to DOX =10) was used to evaluate the sensitization effect of AICAR with lowdose DOX concentration. The resulting nanoparticles [(1) $\mathrm{Fe}_{3} \mathrm{O}_{4} @ \mathrm{SiO}_{2}$ (FITC)-FA/AICAR; (2) $\mathrm{Fe}_{3} \mathrm{O}_{4} @ \mathrm{SiO}_{2}$ (FITC)FA/DOX; (3) $\mathrm{Fe}_{3} \mathrm{O}_{4} @ \mathrm{SiO}_{2}$ (FITC)-FA/AICAR/DOX] were magnetically separated and washed with ultrapure water several times to remove any unreacted reactants and dried under vacuum at room temperature, overnight.

Structural and Physicochemical Characterization. Dynamic light scattering (DLS) measurements were performed at $25^{\circ} \mathrm{C}$, using a Malvern Zetasizer NanoZS compact scattering spectrometer. The average hydrodynamic diameters, the size distributions and the surface charge analysis of the samples were determined using Malvern Dispersion Technology Software 7.11. Nanoparticles were suspended in ultrapure water $\left(\mathrm{Fe}_{3} \mathrm{O}_{4}\right.$ nanoparticles in hexane $)$ to give optimum signal intensity. All measurements were repeated three times to verify the reproducibility of the results.
Powder X-ray diffraction (XRD) measurements were performed with "Philips X'Pert Pro", at room temperature by using $\mathrm{Cu} \mathrm{K} \alpha$ radiation $(\lambda=1.5405 \AA)$ and Bragg-Brentano $\theta / 2 \theta$ configuration. The measurements were performed over the $2 \theta$ range of $15-70^{\circ}$.

The Fourier transform infrared spectroscopy (FTIR) spectra of the nanoparticles were collected with a "PerkinElmer Spectrum-100" spectrophotometer in the range 450$4000 \mathrm{~cm}^{-1}$. The spectra of the dried samples were obtained by employing a $\mathrm{KBr}$ pellet.

Thermogravimetric analysis (TGA) was performed on a PerkinElmer Diomand TG/DTA Instruments from room temperature to $650{ }^{\circ} \mathrm{C}$ with a heating rate of $10{ }^{\circ} \mathrm{C} / \mathrm{min}$ in a nitrogen flow.

Scanning electron microscopy (SEM) and energy-dispersive $\mathrm{X}$-ray spectroscopy (EDX) studies were performed at a high resolution environmental scanning electron microscope (FEI Quanta $250 \mathrm{FEG}$ ) equipped with an energy-dispersive X-ray spectrometer (Oxford AZtec). Prior to examination, the lyophilized nanoparticles were placed on a double stick tape over aluminum stubs to get a uniform layer of particles.

Scanning transmission electron microscopy (STEM) images of the final nanoparticles were obtained with a "FEI Quanta 250 FEG" microscope operating with STEM Detector. The nanoparticles were dispersed in water under sonication and a drop was placed on a carbon-coated 400 mesh copper grid followed by air-drying.

Cellular Uptake Analysis. Internalization of the nanoparticles was visualized using an Olympus IX2-ILL100 fluorescence microscope equipped with an appropriate filter set. Images were acquired using a CCD camera and analyzed using ImageJ advanced version software. A549, HCT-116, HeLa, Jurkat, and MIA PaCa- 2 cells $\left(1 \times 10^{5}\right.$ cells/well $)$ were seeded in 12-well plates overnight before experiments. $\mathrm{Fe}_{3} \mathrm{O}_{4} @$ $\mathrm{SiO}_{2}$ (FITC)-FA/AICAR/DOX nanoparticles were added into the incubation medium at concentrations of $10 \mu \mathrm{g} / \mathrm{mL}$ for $4 \mathrm{~h}$ incubation in $5 \% \mathrm{CO}_{2}$ at $37{ }^{\circ} \mathrm{C}$. All cells except Jurkat (suspension cells) and MIA PaCa-2 (suspension/adherent mixed cells) were washed twice with phosphate-buffered saline (PBS). Microscopic images in the green channel for detection of the FITC label encapsulated in nanoparticles and in the bright-field were obtained by fluorescence microscopy.

Cytotoxicity of Multifunctional Nanoparticles. The cytotoxicity of the prepared nanoparticles were evaluated by 3-(4,5-dimethylthialzol-2-yl)-2,5-diphenyltetrazolium bromide (MTT) assay. A549, HCT-116, HeLa, Jurkat, and MIA $\mathrm{PaCa}-2$ cells were seeded into 96-well plates at a density of $1 \times 10^{4}$ per well in $100 \mu \mathrm{L}$ of media and grown overnight. The cells were then incubated with various concentrations $(0.1 / 1.0 /$ $10 / 50 / 100 / 200 \mu \mathrm{g} / \mathrm{mL})$ of nanoparticles for $48 \mathrm{~h}$ at $37{ }^{\circ} \mathrm{C}$ under $5 \% \mathrm{CO}_{2}$. Following this incubation, cells were incubated in medium containing $0.5 \mathrm{mg} / \mathrm{mL}$ of MTT for $4 \mathrm{~h}$. The medium was discarded, and the precipitated formazan violet crystals were dissolved in $150 \mu \mathrm{L}$ of DMSO to solubilize the formazan. After shaking the plate for $10 \mathrm{~min}$, the absorbance of the sample was measured at $570 \mathrm{~nm}$ by multidetection microplate reader. The absorbance of dissolved formazan in the visible region correlates with the number of intact active cells. The cytotoxicity was evaluated with reference to the $\mathrm{IC}_{50}$ value that was defined as the concentration needed for a $50 \%$ reduction of survival based on the survival curves. $\mathrm{IC}_{50}$ values were calculated from dose-response curves (nanoparticle concentration vs cell survival fraction) obtained in multireplicated 
experiments. For the combination treatment studies, the cells were incubated with (1) $\mathrm{Fe}_{3} \mathrm{O}_{4} @ \mathrm{SiO}_{2}$ (FITC)-FA blank nanoparticles as control, (2) $\mathrm{Fe}_{3} \mathrm{O}_{4} @ \mathrm{SiO}_{2}$ (FITC)-FA/AICAR nanoparticles containing only inhibitor, (3) $\mathrm{Fe}_{3} \mathrm{O}_{4} @ \mathrm{SiO}_{2}(\mathrm{FITC})-$ FA/DOX nanoparticles containing only drug, or (4) $\mathrm{Fe}_{3} \mathrm{O}_{4} @$ $\mathrm{SiO}_{2}$ (FITC)-FA/AICAR/DOX nanoparticles containing both inhibitor and drug to test the efficacy of nanoparticles on cancer cell growth.

Statistical Analysis. All data were represented as means \pm standard deviation (SD). Statistical analysis was performed with the Student's $t$ test, using Excel Software (Microsoft). A $P$ value of $\leq 0.05$ was considered statistically significant.

\section{AUTHOR INFORMATION}

\section{Corresponding Author}

*E-mail: cenkdaglioglu@iyte.edu.tr. Phone: +90 2327507319. Fax: +90 2327507303 .

\section{Notes}

The authors declare no competing financial interest.

\section{ACKNOWLEDGMENTS}

The authors would like to thank Professor Anne Frary for proofreading of the manuscript and staff of The Center for Materials Research of Izmir Institute of Technology for their technical support.

\section{REFERENCES}

(1) Longley, D. B., and Johnston, P. G. (2005) Molecular mechanisms of drug resistance. J. Pathol. 205, 275-292.

(2) Chabner, B. A., and Roberts, T. G., Jr. (2005) Timeline: Chemotherapy and the war on cancer. Nat. Rev. Cancer 5, 65-72.

(3) Yague, E., and Raguz, S. (2005) Drug resistance in cancer. Br. J. Cancer 93, 973-976.

(4) Pennati, M., Folini, M., and Zaffaroni, N. (2007) Targeting survivin in cancer therapy: fulfilled promises and open questions. Carcinogenesis 28, 1133-9.

(5) Fukuda, S., and Pelus, L. M. (2006) Survivin, a cancer target with an emerging role in normal adult tissues. Mol. Cancer Ther. 5, 108798.

(6) Pennati, M., Folini, M., and Zaffaroni, N. (2008) Targeting survivin in cancer therapy. Expert Opin. Ther. Targets 12 (4), 463-476.

(7) Meli, M., Pennati, M., Curto, M., Daidone, M. G., Plescia, J., Toba, S., Altieri, D. C., Zaffaroni, N., and Colombo, G. (2006) Smallmolecule targeting of heat shock protein 90 chaperone function: rational identification of a new anticancer lead. J. Med. Chem. 49, $7721-7730$.

(8) Kizek, R., Adam, V., Hrabeta, J., Eckschlager, T., and Smutny, S. (2012) Anthracyclines and ellipticines as DNA-damaging anticancer drugs: recent advances. Pharmacol. Ther. 133, 26-39.

(9) Smith, L., Watson, M. B., and O'Kane, S. L. (2006) The analysis of doxorubicin resistance in human breast cancer cells using antibody microarrays. Mol. Cancer Ther. 5, 2115-2120.

(10) Minotti, G., Menna, P., Salvatorelli, E., Cairo, G., and Gianni, L. (2004) Anthracyclines: molecular advances and pharmacologic developments in antitumor activity and cardiotoxicity. Pharmacol. Rev. 56, 185-229.

(11) Gao, J. H., Gu, H. W., and Xu, B. (2009) Multifunctional magnetic nanoparticles: design, synthesis, and biomedical applications. Acc. Chem. Res. 42, 1097-1107.

(12) Wang, X., Ramstrom, O., and Yan, M. (2011) Dye-doped silica nanoparticles as efficient labels for glycans. Chem. Commun. 47, 42614263.

(13) Kim, J., Piao, Y., Lee, N., Park, Y. I., Lee, I.-H., Lee, J.-H., Paik, S. R., and Hyeon, T. (2010) Magnetic nanocomposite spheres decorated with $\mathrm{NiO}$ nanoparticles for a magnetically recyclable protein separation system. Adv. Mater. 22, 57-60.
(14) Lee, J. E., Lee, N., Kim, H., Kim, J., Choi, S. H., Kim, J. H., Kim, T., Song, I. C., Park, S. P., Moon, W. K., et al. (2010) Uniform mesoporous dye-doped silica nanoparticles decorated with multiple magnetite nanocrystals for simultaneous enhanced magnetic resonance imaging, fluorescence imaging, and drug delivery. J. Am. Chem. Soc. 132, 552-7.

(15) Pan, Y., Du, X., Zhao, F., and Xu, B. (2012) Magnetic nanoparticles for the manipulation of proteins and cells. Chem. Soc Rev. 41, 2912-2942.

(16) Mulder, W. J. M., Koole, R., Brandwijk, R. J., Storm, G., Chin, P. T. K., Strijkers, G. J., de Mello Donega, C., Nicolay, K., and Griffioen, A. W. (2006) Quantum dots with a paramagnetic coating as a bimodal molecular imaging probe. Nano Lett. 6, 1-6.

(17) Zhao, X., Li, H., and Lee, R. J. (2008) Targeted drug delivery via folate receptors. Expert Opin. Drug Delivery 5, 309-319.

(18) Lu, Y., and Low, P. S. (2002) Folate-mediated delivery of macromolecular anticancer therapeutic agents. Adv. Drug Delivery Rev. 54, 675-693.

(19) Reddy, J. A., Allagadda, V. M., and Leamon, C. P. (2005) Targeting therapeutic and imaging agents to folate receptor positive tumors. Curr. Pharm. Biotechnol. 6, 131-150.

(20) Hyeon, T., Lee, S. S., Park, J., Chung, Y., and Na, H. B. (2001) Synthesis of highly crystalline and monodisperse maghemite nanocrystallites without a size-selection process. J. Am. Chem. Soc. 123, 12798-12801.

(21) Lu, C.-W., Hung, Y., Hsiao, J.-K., Yao, M., Chung, T.-H., Lin, Y.S., Wu, S.-H., Hsu, S-Ch., Liu, H.-M., Mou, C.-Y., et al. (2007) Bifunctional magnetic silica nanoparticles for highly efficient human stem cell labeling. Nano Lett. 7 (1), 149-154.

(22) Pereira, C., Pereira, A. M., Quaresma, P., Tavares, P. B., Pereira, E., Araújo, J. P., and Freire, C. (2010) Superparamagneticc-Fe2O3@ SiO2nanoparticles: a novel support for the immobilization of [VO(acac)2]. Dalton Trans. 39 (11), 2842-2854.

(23) Daglioglu, C., and Zihnioglu, F. (2012) Covalent immobilization of trypsin on glutaraldehyde-activated silica for protein fragmentation. Artif. Cells Blood Subst. and Biotechnol. 40, 378-384.

(24) Yoon, T. J., Kim, J. S., Kim, B. G., Yu, K. N., Cho, M. H., and Lee, J. K. (2005) Multifunctional nanoparticles possessing A "Magnetic Motor Effect" for drug or gene delivery. Angew. Chem., Int. Ed. 44, 1068-1071.

(25) Lopez, K. A., Pina, M. N., Alemany, R., Vogler, O., Barcelo, F., and Morey, J. (2014) Antifolate-modified iron oxide nanoparticles for targeted cancer therapy: inclusion vs. covalent union. RSC Adv. 4, 19196-19204.

(26) Laurent, S., Forge, D., Port, M., Roch, A., Robic, C., vander Elst, L., and Muller, R. N. (2008) Magnetic iron oxide nanoparticles: synthesis, stabilization, vectorization, physicochemical characterizations, and biological applications. Chem. Rev. 108 (6), 2064-2110.

(27) Zhang, M., Cushing, B. L., and O'Connor, C. J. (2008) Synthesis and characterization of monodisperse ultra-thin silica-coated magnetic nanoparticles. Nanotechnology 19, 085601.

(28) Li, Y., Dong, C., Chu, J., Qi, J., and Li, X. (2011) Surface molecular imprinting onto fluorescein-coated magnetic nanoparticles via reversible addition fragmentation chain transfer polymerization: A facile three-in-one system for recognition and separation of endocrine disrupting chemicals. Nanoscale 3, 280.

(29) Yang, K., Peng, H., Wen, Y., and Li, N. (2010) Re-examination of characteristic FTIR spectrum of secondary layer in bilayer oleic acid-coated Fe3O4nanoparticles. Appl. Surf. Sci. 256, 3093-3097.

(30) Belin, T., Guigue-Millot, N., Caillot, T., Aymes, D., and Niepce, J. C. (2002) Influence of grain size, oxygen stoichiometry, and synthesis conditions on the $\gamma$-Fe2O3 vacancies ordering and lattice parameters. J. Solid State Chem. 163, 459-465.

(31) Palma, R., de Trekker, J., Peeters, S., Van Bael, M. J., Bonroy, K., Wirix-Speetjens, R., Reekmans, G., Laureyn, W., Borghs, G., and Maes, G. (2007) Surface modification of g-Fe2O3@SiO2 magnetic nanoparticles for the controlled interaction with biomolecules. J. Nanosci. Nanotechnol. 7 (12), 4626-41. 
(32) Dutta, R. K., Sharma, P. K., and Pandey, A. C. (2010) Design and surface modification of potential luminomagnetic nanocarriers for biomedical applications. J. Nanopart. Res. 12, 1211-1219.

(33) Muhammad, F., Guo, M., Guo, Y., Qi, W., Qu, F., Sun, F., Zhao, H., and $\mathrm{Zhu}, \mathrm{G}$. (2011) Acid degradable $\mathrm{ZnO}$ quantum dots as a platform for targeted delivery of an anticancer drug. J. Mater. Chem. 21, 13406-13412.

(34) Ami, D., Mereghetti, P., and Doglia, S. M. (2013) Multivariate analysis for fourier transform infrared spectra of complex biological systems and processes. Multivariate Analysis in Management, Engineering and the Sciences (Freitas, L., MSc., Ed.) ISBN: 978-953-510921-1. DOI: $10.5772 / 53850$

(35) Sudimack, J., and Lee, R. J. (2000) Targeted drug delivery via the folate receptor. Adv. Drug Delivery Rev. 41, 147-162.

(36) Yonesaka, K., Tamura, K., Kurata, T., Satoh, T., Ikeda, M., Fukuoka, M., and Nakagawa, K. (2006) Small interfering RNA targeting survivin sensitizes lung cancer cell with mutant p53 to Adriamycin. Int. J. Cancer 118, 812-820.

(37) Ghosh, S. K., Yigit, M. V., Uchida, M., Ross, A. W., Barteneva, N., Moore, A., and Medarova, Z. (2014) Sequence-dependent combination therapy with doxorubicin and a survivin-specific small interfering RNA nanodrug demonstrates efficacy in models of adenocarcinoma. Int. J. Cancer 134 (7), 1758-1766.

(38) Jackson, A. L., and Linsley, P. S. (2010) Recognizing and avoiding siRNA off-target effects for target identification and therapeutic application. Nat. Rev. Drug Discovery 9 (1), 57-67. 